Elsevier required licence: (C) <2021>. This manuscript version is made available under the CC-BY-NCND 4.0 license http://creativecommons.org/licenses/by-nc-nd/4.0/

The definitive publisher version is available online at

[https://www.sciencedirect.com/science/article/pii/S0950061821007145?via\%3Dihub] 
3

4

\section{Genetic Programming to Formulate Viscoelastic Behavior of Modified Asphalt Binder}

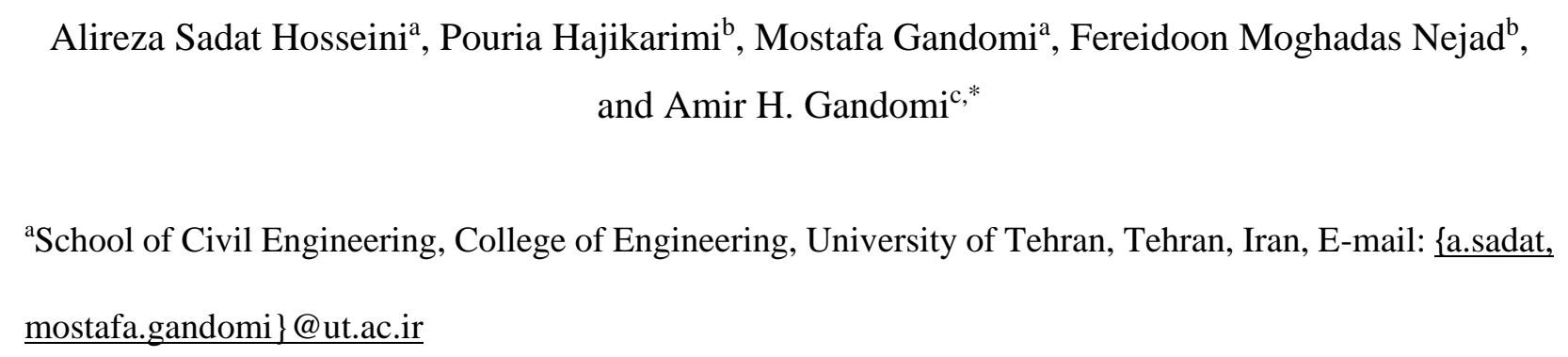

${ }^{\text {aS }}$ chool of Civil Engineering, College of Engineering, University of Tehran, Tehran, Iran, E-mail: \{a.sadat, mostafa.gandomi\}@ut.ac.ir

${ }^{\mathrm{b}}$ Department of Civil \& Environmental Engineering, Amirkabir University of Technology (Tehran Polytechnic), Tehran, Iran, E-mail: \{phajikarimi, moghadas\}@aut.ac.ir

${ }^{\mathrm{c}}$ Faculty of Engineering \& Information Technology, University of Technology Sydney, Sydney, Australia, E-mail: gandomi@uts.edu.au 


\section{Genetic Programming to Formulate Viscoelastic Behavior of Modified Asphalt Binder}

\section{Abstract}

The objective of this research was to develop prediction models for complex shear modulus $\left(\mathrm{G}^{*}\right)$ and phase angle $(\delta)$ of bitumens modified with crumb rubber, styrene-butadiene styrene, and polyphosphoric acid at low and moderate temperatures. The experiments consisted of three different dosages of each modifier added to the original bitumen followed by measurement of $\mathrm{G}^{*}$ and $\delta$ of the original and modified bitumen using the dynamic shear rheometer (DSR) test in frequency sweep mode (21 loading frequencies from 0.1 to $100 \mathrm{~Hz}$ ) at seven test temperatures: $22,-16,-10,0,10,16$ and $22^{\circ} \mathrm{C}$. Having the experimental database, a robust genetic programming (GP) method was used to develop an individual prediction model for each modifier based on temperature, loading frequency, the $\mathrm{G}^{*}$ and $\delta$ of the original bitumen, and the dosage of the modifier. Results showed that GP successfully developed accurate and meaningful expressions for calculating $\mathrm{G}^{*}$ and $\delta$ of the modified bitumen as two main constitutive components of the viscoelastic behavior of bituminous composites. Then, a parametric study and sensitivity analysis were performed on the developed models to better understand the effect of variables on the trend of the models. The modifier dosage is the most effective input variable of the model and the amount of $\mathrm{G}^{*}$ and $\delta$ of the original bitumen accurately reflect the effect of temperature and loading frequency on viscoelastic behavior of the modified bitumen, as they behave linearly at the considered test temperatures.

Keywords: Genetic Programming, Modified Asphalt, Viscoelastic, Crumb rubber, SBS, PPA 


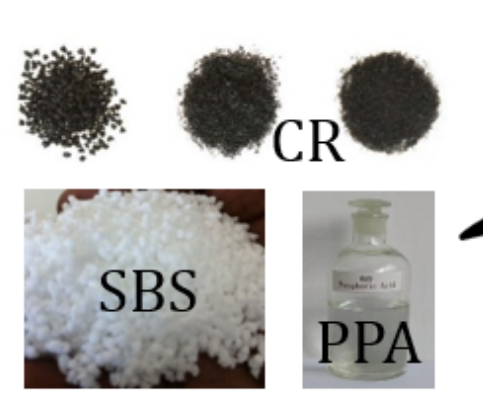

Additives

\section{Introduction}

Modification of original bitumen is a well-known method for improving its rheological and mechanical properties in order to meet the standard criteria and for increasing the life span of asphalt pavement. There are several additives used to enhance the low-, moderate-, and hightemperature performance of original bitumen, which can be selected based on climate conditions and dominant distress. Numerous previous publications investigated the effect of such additives on mechanical behavior, durability, and workability characteristics of original bitumen [1][2][3].

One of the major concerns regarding bitumen that is modified with different dosages of additives is precisely predicting its viscoelastic characteristics at the desired loading frequency, temperature, and additive concentration. Experimental and numerical modeling were used for this purpose, which assumed a simple thermo-rheological behavior of the original and modified bitumen. 
50 Although such an assumption can work for relating time and temperature based on the time-

51 temperature superposition principle (TTSP), it is difficult for these equations to account for

52 additive dosage. Therefore, prediction models such as GP can be used to intelligently predict the

53 viscoelastic behavior of modified bitumen that has additional dosage and viscoelastic

54 characteristics relative to the original bitumen.

55 GP, which in general is defined as a specialization of genetic algorithm (GA), is a powerful method

56 for optimizing complex problems and uses computer-based programs instead of binary strings to

57 solve problems [4]. GP has an inherent superiority over conventional mathematical and statistical

58 approaches and black-box algorithms such as ANN, which is the ability of GP to produce explicit

59 equations without using initial prediction models that present the relation between the involved

60 parameters. This ability can be easily implemented in the practical design of modified asphalt

61 binders. A recent extension of GP is gene expression programming (GEP), which was proposed

62 by Ferreira [5]. Computer programs of different sizes and shapes are encoded in linear

63 chromosomes of fixed length and comprise the GEP solutions. In order to predict the complex

64 relationships between inputs and outputs of a data source, researchers presented methodologies for

65 using GP to generate prediction formulae for engineering problems [6].

66 Gholampour et al. [7] applied the GEP technique on a large test database to develop formulae with

67 a wide range of applicability for predicting the mechanical properties of recycled aggregate

68 concrete. To predict the dynamic modulus, which is one of the most important mechanical property

69 parameters of asphalt concrete, Liu et. al [8] explored two different GEP approach models for hot

70 mix asphalt (HMA) and mixtures containing recycled asphalt shingles. The GEP approach was

71 implemented in order to develop a prediction model of density and viscosity of bitumen [9].

72 Results of the presented model were compared with traditional empirical models in order to 
73 investigate its performance. To predict fracture energy of asphalt concrete specimens, Majidifard

74 et al. used GEP and hybrid artificial neural network/simulated annealing (ANN/SA) by 75 implementing an experimental database containing results of disk-shaped compact tension 76 (DC(T)) tests. More recently, fatigue life prediction of hot mix asphalt (HMA) was formulated 77 using GP [10]. Although several research works used artificial neural network models to predict 78 the rheological and mechanical characteristics of modified bitumens with different types of 79 additives [11][12][13], the GEP has not been used for relating the percentage of additive and other 80 effective parameters to the desired properties of modified bitumen as a closed form equation. Since

81 the mechanism of the effect that different additives have on original bitumen varies regarding the 82 type of its interaction (physical/chemical), intrinsic properties of the original bitumen, and testing 83 conditions, particular equations for each type of additive must be derived. It is well-known that 84 the original and modified bitumen behave as viscoelastic materials in which their characteristics 85 depend on time, temperature, and loading rate. Therefore, an appropriate simple closed form 86 equation should include constitutive properties of the original bitumen, the percentage of additives, 87 and testing conditions to predict the rheological and mechanical characteristics of modified 88 bitumen.

89 In this study, three different prevalent types of additives were selected and were used to modify 90 the original bitumen, which included crumb rubber, styrene-butadiene-styrene (SBS), and 91 polyphosphoric acid (PPA). Each modifier was added to the original bitumen at three different 92 dosages: 10, 15, and $20 \mathrm{wt} . \%$ for crumb rubber, 2 , 4, and $6 \mathrm{wt} . \%$ for SBS, and 0.5, 1 , and $1.5 \mathrm{wt} . \%$ 93 for PPA. Then, two constitutive viscoelastic parameters (complex shear modulus $\left(\mathrm{G}^{*}\right)$ and phase 94 angle $(\delta)$ ) were measured by performing a frequency sweep test at seven different test 95 temperatures: $-22,-16,-10,0,10,16$, and $22^{\circ} \mathrm{C}$. The purpose of this study is to use the GEP 
96 technique to predict $\mathrm{G}^{*}$ and $\delta$ of modified bitumen based on these parameters measured for the

97 original bitumen. Such a model will make it possible to find the optimum dosage of each additive

98 in order to achieve the desired viscoelastic properties at low and moderate temperatures. In

99 summary, Figure 1 illustrates the flow of work in this study.

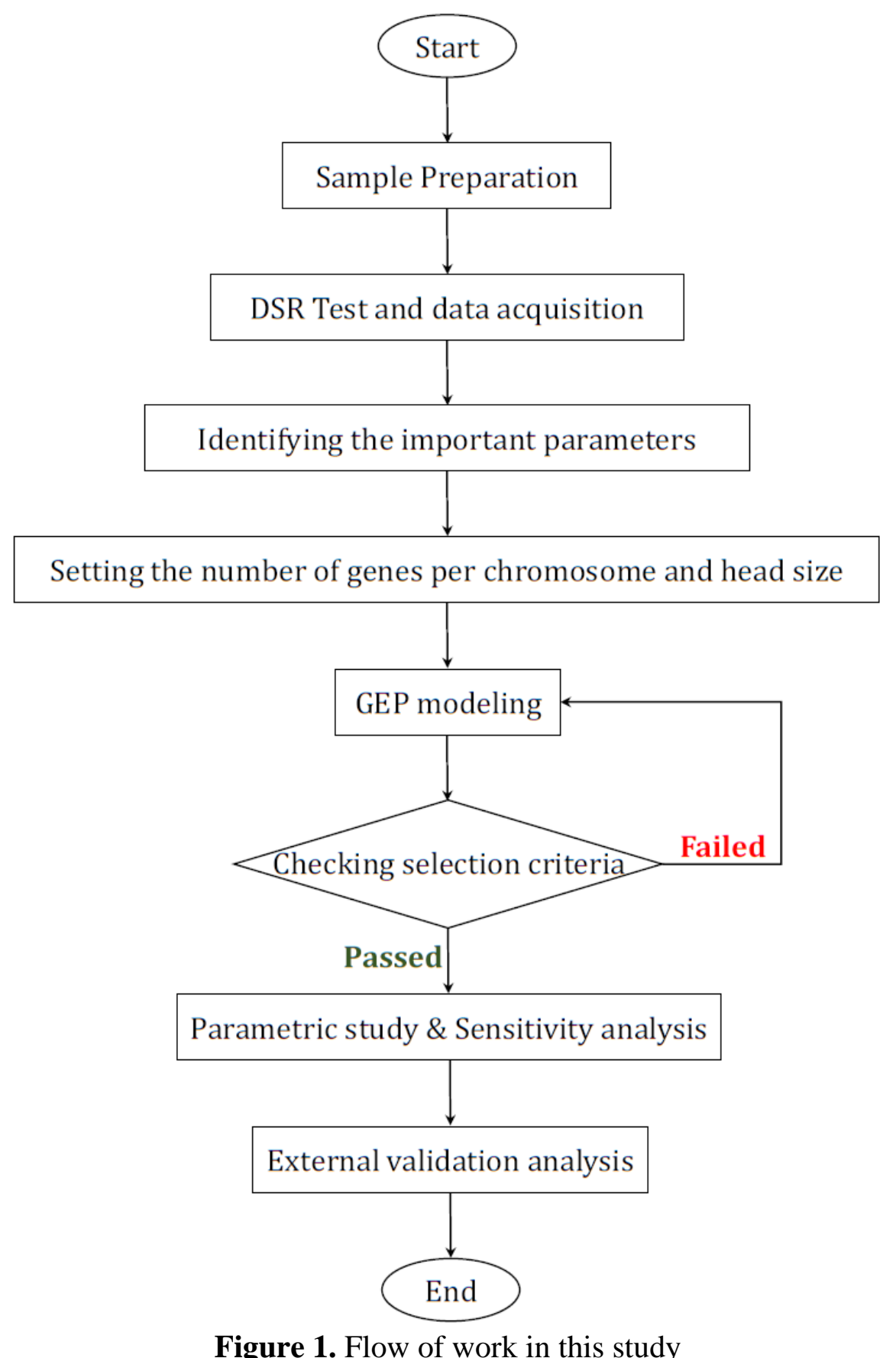


101

102

103

104

105

106

107

108

109

110

111

112

113

114

115

116

117 of the crumb rubber.

\subsection{Modifiers}

\subsubsection{Crumb rubber}

\section{Experimental Program}

In this research, three common types of bitumen additives, including crumb rubber, styrenebutadiene-styrene (SBS) and polyphosphoric acid (PPA), were used to enhance the rheological and mechanical characteristics of the original bitumen. First in this section, these modifiers are briefly introduced; then, sample preparation, the test method, and generated results are presented.

Crumb rubber is one of the oldest modifiers of bitumen used for enhancing its low-temperature cracking resistance in cold regions, improving asphalt concrete fatigue and rutting performance, as well as resolving the difficulties associated with dumping used tire [14][15]. This modifier is generally produced by shredding used tires and classifying the product into different particle sizes. Liu et al. [16] investigated the effect of crumb rubber on the low-temperature performance of bitumen by implementing a bending beam rheometer test; the results showed that the optimum dosage of crumb rubber is between 15 and $20 \%$. Aflaki and his coworkers [17] showed that modified bitumen containing $14 \%$ of rubber particles has a higher dissipated energy ratio and derivation of creep compliance. The crumb rubber used in this study was passed through sieve \#50 obtained from Yazd Isatis Company. Table 1 shows the physical and chemical properties

Table 1. Physical and chemical properties of crumb rubber

\begin{tabular}{lll}
\hline Test Item & Result & Test Method \\
\hline Specific Gravity $\left(\mathbf{g r} / \mathbf{c m}^{\mathbf{3}}\right)$ & 0.395 & ASTM-D70-03 \\
Acetone Extract $(\mathbf{w t} \%)$ & 21.6 & ASTM-D494-11 \\
Ash Content (wt\%) & 11 & ASTM-D4574 \\
Percent Rubber Hydrocarbon (wt\%) & 49 & ASTM-D297 \\
Mooney Viscosity at $\mathbf{1 0 0}^{\circ} \mathbf{C}(\mathbf{M L})$ & 56 & ASTM-D1646 \\
\hline
\end{tabular}




\begin{tabular}{lll}
\hline Tensile Strength (MPa) & 48 & ASTM-D412 \\
Elongation (\%) & 212 & ASTM-D1456 \\
Hardness (Shore A) & 63 & ASTM-D2240 \\
\hline
\end{tabular}

120

$121 \quad$ 2.1.2. Styrene-butadiene-styrene (SBS)

122 SBS is the most prevalent modifier of bitumen and has a wide range of applications [18]. It is an

123 elastomer comprised of SBS tri-block chains with a two-phase morphology of spherical

124 polystyrene block domains within a matrix of polybutadiene. A continuous polymer phase is

125 formed within the bitumen structure if an appropriate SBS dosage (commonly 5-7\% by mass of

126 the original bitumen) is added to the original bitumen. The SBS used in this study was C-502 that

127 has a linear structure and was acquired from Dynasol. Table 2 shows the physical, chemical, and 128 thermo-mechanical characteristics of the SBS.

Table 2. Physical, chemical and thermo-mechanical properties of SBS

\begin{tabular}{ccc}
\hline Property & Value & Comment \\
\hline Volatiles & $<=0.40 \%$ & ASTM D-5668 \\
Viscosity & $1600 \mathrm{cP}$ & Modified Bitumen Property in waterproof membranes (150/200 \\
& $@$ Temperature & bitumen + 12\% polymer) \\
Brookfield & $180{ }^{\circ} \mathrm{C}$ & $25 \%$ toluene solution; MA 04-3-064 \\
Viscosity & $5000 \mathrm{cP}$ & ASTM D-5667 \\
Ash & $<=0.35 \%$ & ASTM D-5775 \\
Styrene Content & $31 \%$ & ASTM D-2240 \\
Hardness, Shore $\mathbf{A}$ & 76 & at $25^{\circ} \mathrm{C}$ dmm, modified bitumen property in waterproof membranes \\
Penetration & $<=55$ & $(150 / 200$ bitumen+12\% polymer); ASTM D-5-86 \\
Ring \& Ball & $>=115{ }^{\circ} \mathrm{C}$ & Modified bitumen property in waterproof membranes $(150 / 200$ \\
boftening Point & & bitumen +12\% polymer); ASTM D-36 \\
\hline
\end{tabular}

131

132 


\subsubsection{Polyphosphoric acid (PPA)}

PPA is a mineral liquid polymer of generic composition $\mathrm{H}_{n+2} \mathrm{P}_{n} \mathrm{O}_{3 n+1}$ [19]. Before the introduction of the Superpave protocol, PPA was being used to improve the penetration index and softening point of bitumen and, after introduction of this protocol, it has been used extensively to enhance binder PG (increasing the interval between high and low service temperatures). Several previous studies investigated the effect of adding PPA on the rheological and mechanical properties of original bitumen, which showed that PPA modification improves the behavior of bitumen in high service temperature [1]. Baldino et al. [20] reported that the effect of PPA on the low-temperature characteristics of bitumen is remarkably dependent on the amount of asphaltene and wax within the original bitumen. Therefore, the type of original bitumen affects the efficiency of PPA modification. The PPA used in this research program was obtained from Merck Millipore. Table 3 depicts the conventional, physical, and chemical properties of PPA.

Table 3. Conventional physical and chemical properties of PPA

\begin{tabular}{lc}
\hline Property & Value \\
\hline Boiling point@ $1013 \mathrm{hPa}$ & $530^{\circ} \mathrm{C}$ \\
Density@ $20^{\circ} \mathrm{C}, \mathrm{gr} / \mathrm{cm}^{3}$ & 2.06 \\
Melting Point & $-20^{\circ} \mathrm{C}$ \\
Vapor pressure@ $20^{\circ} \mathrm{C}, \mathrm{hPa}$ & 2 \\
Assay (acidimetric, calc. as $\left.\mathrm{P}_{2} \mathrm{O}_{5}\right)$ & $83-87 \%$ \\
\hline
\end{tabular}

\subsection{Sample Preparation}

The original bitumen used in this study was PG 58-22, acquired from Pasargad Oil Company located in Tehran, Iran. All modifications were performed based on the weight of the original bitumen. Three different concentrations of each additive were used (Table 4). The dosage of each additive was based on the dosages reported in the technical literature [21][17] shown to improve 
153 the high, moderate, and low-temperature performance of an original bitumen, which are consistent

154 with best practices in the pavement industry. Thus, one original and nine modified samples were

155 fabricated. According to the type of modifier, different blending conditions were used, which are

156 presented in Table 4. The type of mixer used to mix the additive with the original bitumen to

157 achieve a homogeneous blend (high shear homogenizer or low shear conventional mixer), the

158 rotational velocity of the mixer, the time, and the temperature of mixing are given as blending

159 conditions.

160 Table 4. Sample code, modifier dosages and blending conditions of all modified bitumen samples

\begin{tabular}{cccccc}
\hline $\begin{array}{c}\text { Sample } \\
\text { Code }\end{array}$ & Modifier & $\begin{array}{c}\text { Dosage } \\
\text { (wt\% of } \\
\text { original } \\
\text { bitumen) }\end{array}$ & True PG & $\begin{array}{c}\text { Blending Conditions } \\
\left(\mathbf{r p m} \text { :min@ }{ }^{\circ} \mathbf{C}\right)\end{array}$ & Type of Mixer \\
\hline BASE & - & - & $58.3-25.0$ & - & High Shear Mixer \\
\hline CR10 & Crumb & $10 \%$ & $68.3-26.6$ & $4500: 60 @ 180$ & \\
CR15 & rubber & $15 \%$ & $73.6-28.7$ & & High Shear Mixer \\
CR20 & & $20 \%$ & $75.4-30.8$ & & \\
\hline SBS2 & SBS & $2 \%$ & $64.4-26.1$ & $5500: 90 @ 180$ & Low Shear Mixer \\
SBS4 & & $4 \%$ & $71.7-20.1$ & & \\
SBS6 & & $6 \%$ & $77.8-17.6$ & & \\
\hline PPA05 & PPA & $0.5 \%$ & $70.5-21.2$ & $50: 45 @ 150$ & \\
PPA1 & & $1 \%$ & $77.1-17.7$ & & \\
PPA2 & & $2 \%$ & $82.2-14.7$ & & \\
\hline
\end{tabular}

161

162

\subsection{Methodology}

163 Two constitutive viscoelastic properties of the original and modified bitumens, including complex

164 shear modulus $\left(\mathrm{G}^{*}\right)$ and phase angle $(\delta)$, were measured by using an Anton Paar A-101 dynamic

165 shear rheometer (DSR). The frequency sweep mode was performed over a frequency range of 0.1

166 to $100 \mathrm{~Hz}$ (21 frequencies) and at a strain amplitude of $0.01 \%(0.0001 \mathrm{~mm} / \mathrm{mm})$. Use of such a

167 low strain amplitude ensures remaining of the bitumen within the linear viscoelastic range. A 
168 sinusoidal shear strain was applied on the bitumen sample at each frequency and the corresponding

169 shear stress was determined as follows [22]:

$$
\gamma(t)=\gamma_{0} e^{i(\omega t-\delta)}
$$

170

$$
\tau(t)=\tau_{0} e^{i \omega t}
$$

171

172 in which $\gamma(\mathrm{t})$ and $\tau(\mathrm{t})$ are the applied shear strain and captured shear stress, $\tau_{0}$ and $\gamma_{0}$ are stress and

173 strain amplitude, respectively, $\delta$ is phase angle, $\omega$ is the angular frequency, and $t$ is time. Complex

174 shear modulus is defined as:

$$
G^{*}=\frac{\tau_{0}}{\gamma_{0}}
$$

175

176 To investigate the thermo-mechanical behavior of modified bitumens, seven different test 177 temperatures were selected: $-22,-16,-10,0,10,16$ and $22^{\circ} \mathrm{C}$. These test temperatures are 178 consistent with ASTM D 7175. The DSR sample had a diameter of $8 \mathrm{~mm}$ and a gap of $2 \mathrm{~mm}$ was 179 set up between two parallel plates. While ASTM D 7175 can be used for test temperatures between 1804 to $88^{\circ} \mathrm{C}$, it was shown that a similar test setup can be used for sub-zero temperatures [23].

\section{2.4. Database}

182 Figure 2 shows typical results generated by the test method described in section 2.2 for the original 183 bitumen at all test temperatures. As can be seen in Figure 2, the amount of both $\mathrm{G}^{*}$ and $\delta$ are 184 depended on the applied loading frequency and the test temperature. Increasing the test 185 temperature decreased the complex shear modulus $\left(\mathrm{G}^{*}\right)$ and increased the phase angle $(\delta)$. Also, 186 increasing the applied loading frequency caused an increase in $\mathrm{G}^{*}$ and a decrease in $\delta$, since the 
187 bituminous sample had less time to relax the stress due to the applied strain. It is evident that 188 adding different types of additive at various dosages altered the viscoelastic behavior of the 189 original bitumen. For each type and percentage of additive, the complex shear modulus and phase 190 angle curves versus frequency were captured.

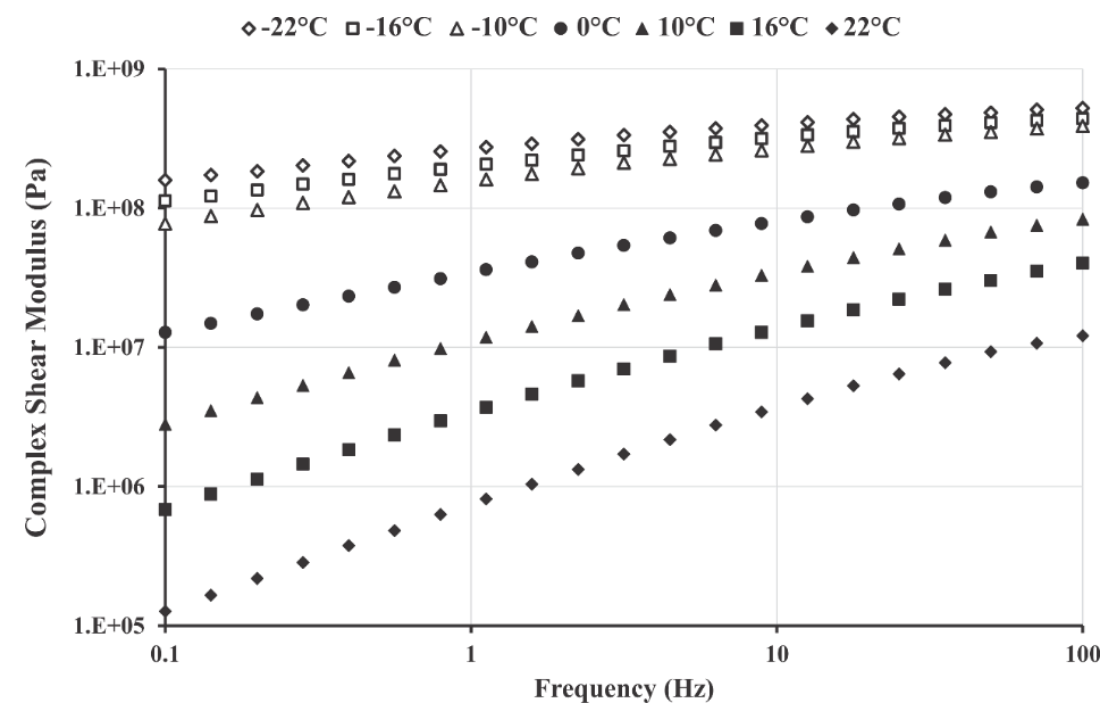

(a)

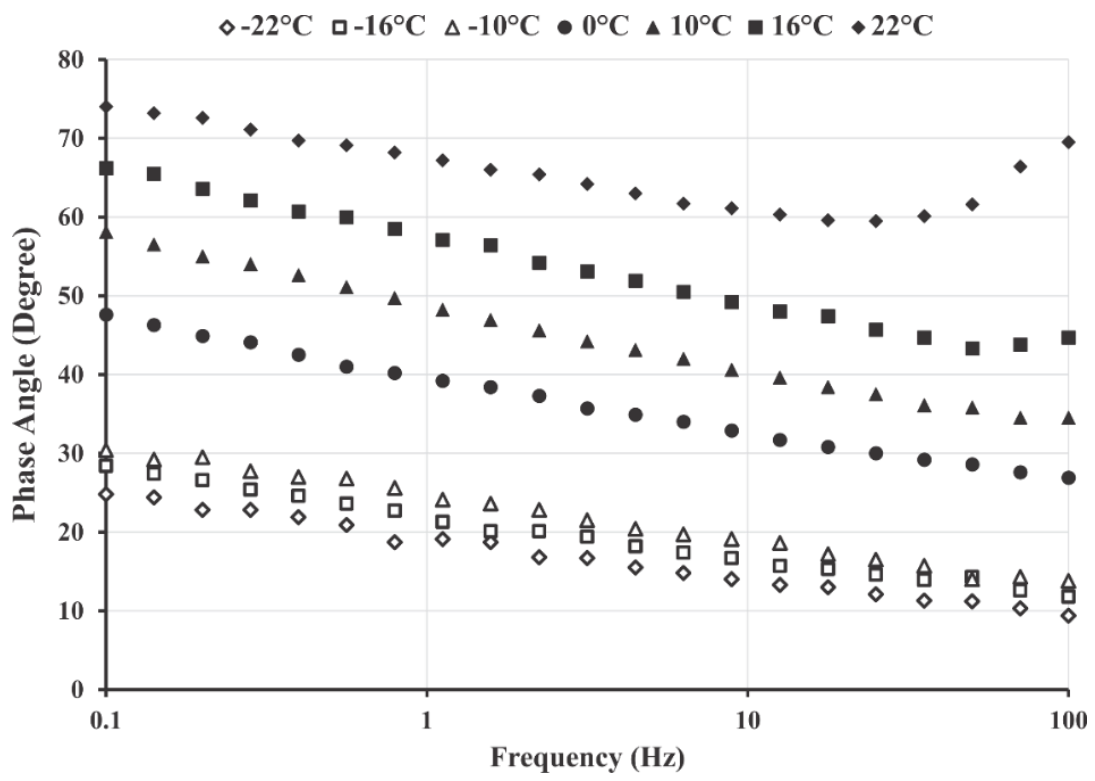

(b)

Figure 2. Results of the frequency sweep test for (a) complex shear modulus, and (b) phase angle of the original bitumen at different test temperatures 
192

193

194

195

196

197

198

199

200

201

202

203

204

205

206

207

208

209

210

211

212

213

\section{Gene Expression Programming (GEP)}

Using GP, which was originally introduced as a useful prediction algorithm by Koza [24], the relationships between the involved parameters of a problem are predicted based on the principle of Darwinian natural selection. The commonly used mechanisms of genetic algorithm (GA) can also be utilized in GP; nevertheless, the solution representation is different. The result of GA is in the form of a fixed-length binary string; however, an evolving GP results in a computer code of prediction can be represented in the form of a tree that varies in length. This is the definition of the classical GP approach, called tree-based GP, which comprises a hierarchically-structured tree of functions and terminals [25]. GEP is basically a natural development of GP and has five main components: (1) a function set, (2) a terminal set, (3) a fitness function, (4) control parameters, and (5) a terminal condition. Unlike the traditional GP, GEP makes use of fixed-length character strings for solution representation. Parsing trees of various sizes, named expression trees (ETs), are a graphical representation of GEP. Because these genetic mechanisms work at the chromosome level, the main advantage of this method is the extreme simplicity of creating genetic diversity.

The other positive aspect of GEP is its multi-genic nature, which makes it possible to evolve complex programs of a high degree of nonlinearity that comprise several subprograms [4].

GEP consists of genes in which each one contains a list of arbitrary fixed-length symbols comprising the terminal set. Therefore, the chromosomes, as an inherent part of GEP, represent a single parse tree. Karva [26] developed a new language that allows the chromosomes' information to be read. Genes that are K-expressions [5] in Karva language are simply comprised of letters representing the problem variables (such as $\mathrm{A}, \mathrm{B}, \mathrm{C}$, etc.) and constant numbers. K-expressions can also be presented in the form of parse trees that are capable of providing information regarding 
214 the mathematical as well as the logical complexity of a gene. For instance, Eq. (4) consists of the

215 gene in Karma language as:

$216 \times$.-.-.+.Ln.A.B.C.5, and can be alternatively illustrated as the ET shown in Figure 3, which starts

217 from the root and reads through the string by sequence.

$$
\exp (5 \times A \times B) \times \frac{C}{A+B}
$$

219 For a given problem, each GEP gene has a predetermined fixed length. However, the useless 220 excessive elements for genome mapping in ETs can change the size of tree [26].

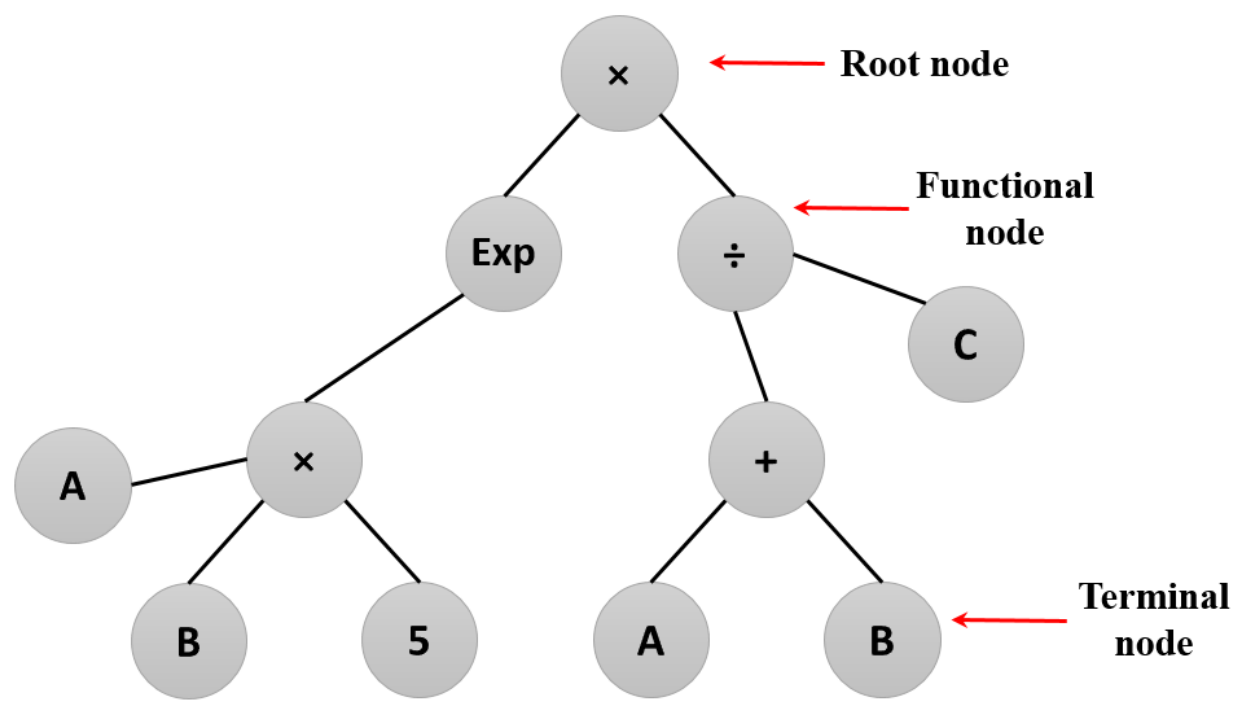

Figure 3. Tree representation of Eq. (1)

223 The GEP algorithm starts with random generation of fixed-length chromosomes of the initial 224 population. Then, k-expressions for each chromosome are produced and evaluated regarding their 225 fitness. Having been selected by roulette wheel sampling with elitism based on the fitness criteria, 226 chromosomes are modified and reproduced. This selection criterion guarantees the maintenance 227 and cloning of the best chromosomes from the previous generation to the next. The new generation 
228

229

230

231

232

233

234

235

236

237

238

239

240

241

242

243

244

245

246

247

248

experiences the same process from the beginning. This procedure is repeated up to a certain number of iterations, or until a solution has been found [5].

\section{Model development}

In order to develop a GP prediction model for estimating the complex shear modulus $\left(\mathrm{G}^{*}\right)$ and phase angle $(\delta)$ of modified asphalt bitumens, all of the effective input parameters that were part of the experimental program have to incorporated into the models. It is well-known that the original bitumen, as well as modified ones, behave like viscoelastic materials and their mechanical behavior depends on time (frequency of applied load) and temperature. The additive dosage used to modify the original bitumen and inherent characteristics of the original bitumen significantly affect the viscoelastic properties of modified bitumen as well. Therefore, $\mathrm{G}^{*}$ and $\delta$, as two constitutive viscoelastic parameters, are functions of the input parameters, as follows:

$$
\begin{gathered}
G^{*}=f\left(G_{0}^{*}, T, \omega, P\right) \\
\delta=f\left(\delta_{0}, T, \omega, P\right)
\end{gathered}
$$

where $G^{*}{ }_{0}(\mathrm{~Pa})$ and $\delta_{0}($ degree) are the complex shear modulus and phase angle of the original bitumen, respectively, $\mathrm{T}$ is the test temperature $\left({ }^{\circ} \mathrm{C}\right), \omega$ is the loading frequency $(\mathrm{Hz})$, and $\mathrm{P}$ is the percentage $(\%)$ of the specific additive (CR, SBS and PPA) that was introduced in order to modify the original bitumen.

\subsection{Statistical analysis of the experimental data}

As per the explanations given in subsection 2.3, the results of the test experiments at different test temperatures and loading frequencies consisted of 1,281 data points for all three modifiers at three different dosages. In order to analyze the data, each set of data for each modifier was randomly 
249 divided into Training and Validation subsets. The training subset for each modifier was used to

250 develop the GP algorithm while the validation data were used to examine how general the

251 predictions of each model were on data that were not used in the training procedure. The best top

252 ten GP models were selected amongst all the developed models using the criteria of having the

253 highest performance in training.Having been selected, the selected models, in terms of learning,

254 were validated against the validation data subset to measure their performance on the data that had 255 no contribution to the model development process. Here, two-thirds of data were used in the 256 training process, while validation analysis was conducted on the remaining one-third.

257 Table 5 illustrates the ranges and statistics of the involved input and output parameters used for 258 model development.

Table 5. Statistics of input and output variables used for the GP model development

\begin{tabular}{|c|c|c|c|c|c|c|c|c|c|c|c|c|c|}
\hline \multirow{2}{*}{$\begin{array}{l}\text { Statistical } \\
\text { Parameter }\end{array}$} & \multicolumn{4}{|c|}{ Common inputs } & \multicolumn{3}{|c|}{$\begin{array}{c}\text { Percentage of } \\
\text { additive, } \mathrm{P}(\%)\end{array}$} & \multicolumn{3}{|c|}{$\mathrm{G}^{*}(\mathrm{~Pa})$} & \multicolumn{3}{|c|}{$\delta(\mathrm{s})$} \\
\hline & $\mathrm{T}\left({ }^{\circ} \mathrm{C}\right)$ & $\omega(\mathrm{Hz})$ & $\mathrm{G}^{*_{0}}(\mathrm{~Pa})$ & $\delta_{0}(\mathrm{~s})$ & $\mathrm{CR}$ & SBS & PPA & $\mathrm{CR}$ & SBS & PPA & $\mathrm{CR}$ & SBS & PPA \\
\hline Range & 44.0 & 99.90 & 522873000 & 64.61 & 10.0 & 4.0 & 1.5 & 371053497 & 5104526334 & 487596944 & 69.19 & 81.01 & 63.53 \\
\hline Minimum & -22.0 & 0.10 & 127000 & 9.39 & 10.0 & 2.0 & 0.5 & 237622 & 113448 & 184139 & 10.38 & 8.98 & 9.25 \\
\hline Maximum & 22.0 & 100.00 & 523000000 & 74.00 & 20.0 & 6.0 & 2.0 & 371291119 & 5105660804 & 487781083 & 79.57 & 90.00 & 72.79 \\
\hline Mean & 0.0 & 16.29 & 132949626 & 36.99 & 15.0 & 4.0 & 1.2 & 76239355 & 113434501 & 98416435 & 32.04 & 35.78 & 36.03 \\
\hline Standard error & - & - & 6964564.82 & 0.88 & - & - & - & 4159385 & 6151394 & 6132163 & 0.67 & 0.85 & 0.74 \\
\hline Standard deviation & - & - & 146089944 & 18.39 & - & - & - & 87248004 & 1290327381 & 122336259 & 14.07 & 17.80 & 14.69 \\
\hline Variance & - & - & $2.1342 \mathrm{E}+16$ & 338.02 & - & - & - & $7.612 \mathrm{E}+15$ & $1.665 \mathrm{E}+16$ & $1.497 \mathrm{E}+161$ & 197.89 & 316.97 & 215.80 \\
\hline $\begin{array}{c}\text { Confidence level } \\
(95.0 \%)\end{array}$ & - & - & 13634810.9 & 1.72 & - & - & - & 8142997 & 12042834 & 12003747 & 1.31 & 1.66 & 1.44 \\
\hline
\end{tabular}

\subsection{Evaluation of model performance}

262 As explained above, all data were divided into Training and Validation groups. Checks of

263 validation and training performance of GP models was performed based on three main objectives:

264 1) the best fitness value and the least amount of error for the training subset, 2) the best fitness 
265 value and the least amount of error for the validation subset on the trained model, and 3) model

266 simplicity. The latter was not a predominant and highly determining parameter and was controlled

267 by setting the genes and head size of each model for the runs. The first and second criteria were

268 controlled for the models in order to examine how accurate the predictions were, using correlation

269 coefficient (R), the relative root mean squared error (RRMSE), and Performance index (PI), as

270 follows:

$$
\begin{aligned}
& R=\sum(O-\bar{O}) \cdot(P-\bar{P}) / \sqrt{\sum(O-\bar{O})^{2} \cdot \sum(P-\bar{P})^{2}} \\
& R R M S E=\sqrt{\frac{1}{n} \sum(O-P)^{2}} \\
& P I=\frac{R R M S E}{1+R}
\end{aligned}
$$

271 where $O$ and $P$ are experimental and predicted outputs, respectively; $\bar{O}$ and $\bar{P}$ are the average of

272 actual and calculated outputs, respectively, and $n$ is the number of samples. These criteria indicate

273 the prediction accuracy of GP models for the training subset.

274 A higher R together with lower RRMSE and PI values result in more accurate model predictions.

\section{4.3. GEP modeling and Formulation}

276 The GEP models were generated using five input parameters for each additive: T, $\omega, G_{0}{ }^{*}, \delta_{0}$, and

$277 \mathrm{P}$, since each additive had a special effect on the viscoelastic behavior of the original bitumen due 278 to its inherent characteristics. In order to derive an accurate GEP model for each target parameter, 279 several runs were conducted using R and the RRMSE as the accuracy controllers. In GP modeling, 280 the population size (number of chromosomes) determines the number of evolved programs. 281 Meanwhile, the appropriate population size depends on the complexity of the problem and the 
282 number of possible solutions for the problem. In the analyses, three sets were set for the population

283 number $(50,150$, and 300).

284 The number of genes per chromosome and head size, known as architectural parameters of the 285 GEP, can determine the structure of each term in each model. The former is used for determining 286 the number of terms in the model, while the latter determines the complexity of each term in the 287 model. Three genes (1, 2, and 3), and three optimal levels of head size (3, 5, and 8) were selected. 288 For a number of genes greater than 1, an extra linking function was used in order to link the 289 encoded mathematical terms of each. With three sets for population size (three genes and three 290 head sizes), a total of 27 different combinations of the parameters existed. Since ten replications 291 for each combination were performed, the overall number of GEP runs was 270.

292 Basic arithmetic operators together with the most common mathematical functions were used to 293 derive the GEP models for each target parameter. Amongst the generated models for each modified 294 bitumen, those with the highest R and the lowest RRMSE were selected. Between the top ten 295 statistically selected models, one model for each target parameter was selected, based on the 296 theoretical fundamentals of the problem explained in the experimental program section. The GEP 297 algorithm was implemented using GeneXproTools [27].

298 The best GEP models were selected according to the previously mentioned criteria of selection. 299 Figures 4 to 6 show the ETs for the best models developed for CR, SBS, and PPA additives, 300 respectively. It is worth noting that the exponential operator was observed in all the selected top 301 ten models of $\mathrm{G}^{*}$ prediction for all three additives. This interesting outcome amongst a great 302 number of generations of GEP training can be attributed to the ideal form of the exponential 303 operator for prediction of the modified complex shear modulus of modified bitumen. 


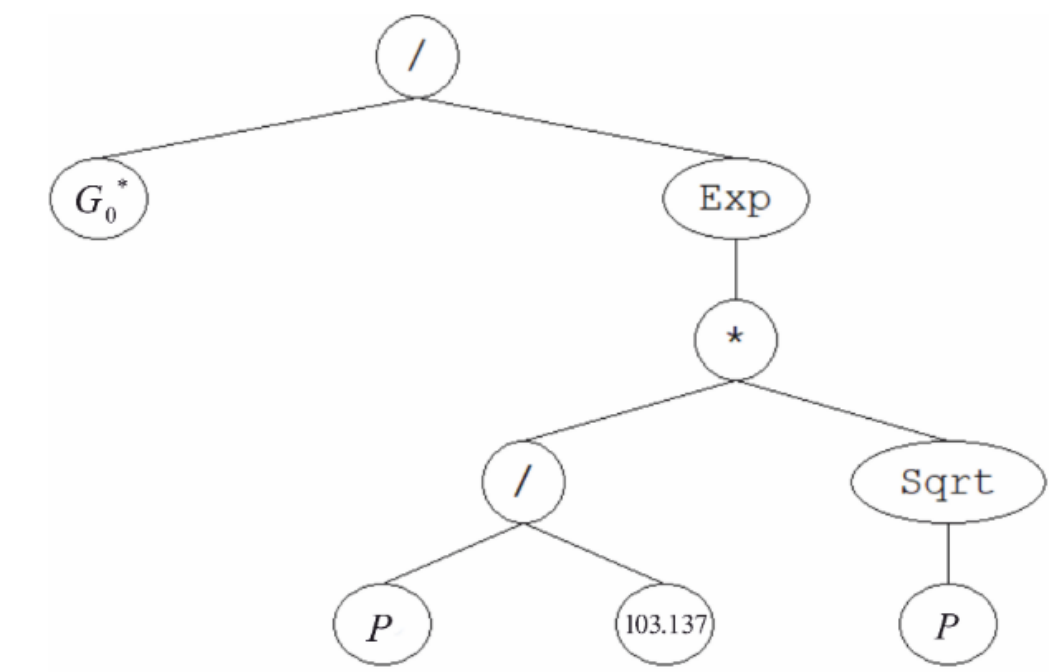

(a)

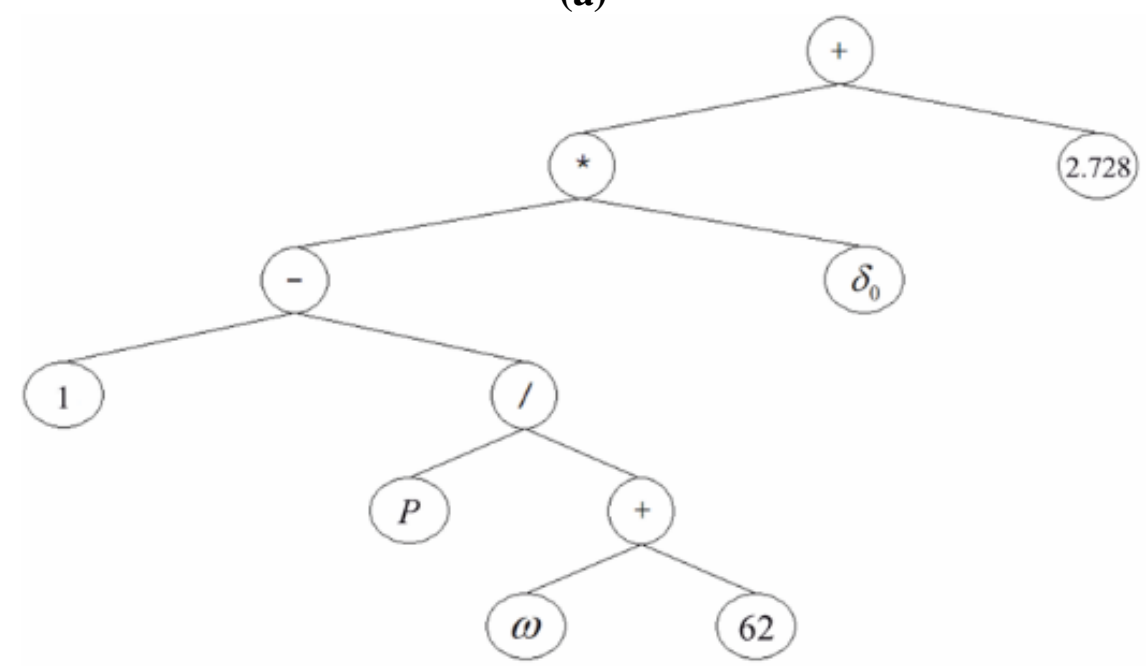

(b)

Figure 4. The best GEP model Tree representation for crumb rubber modified bitumen a) 


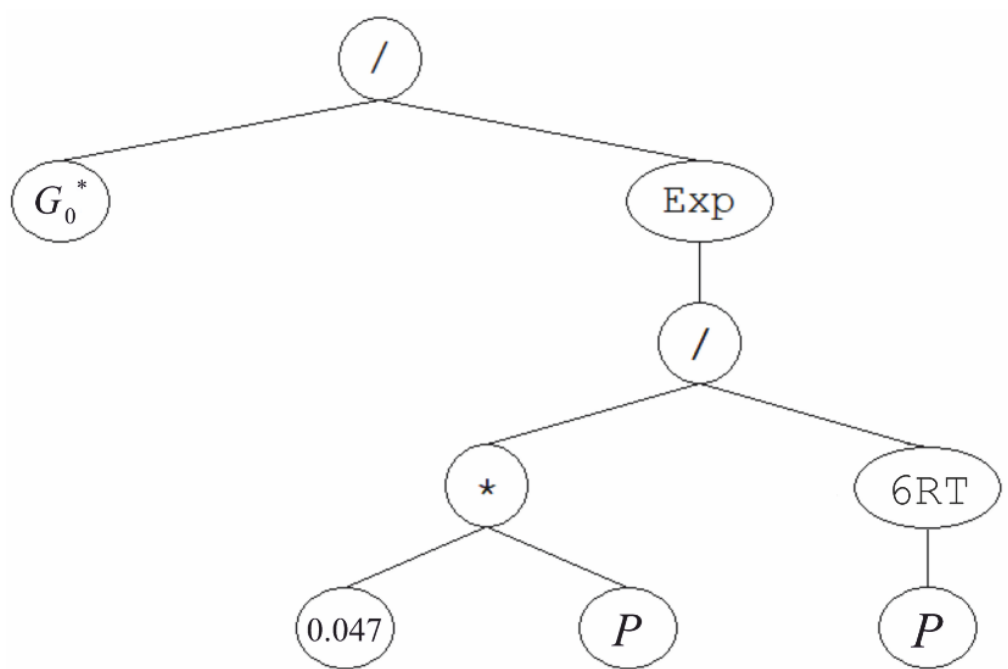

(a)
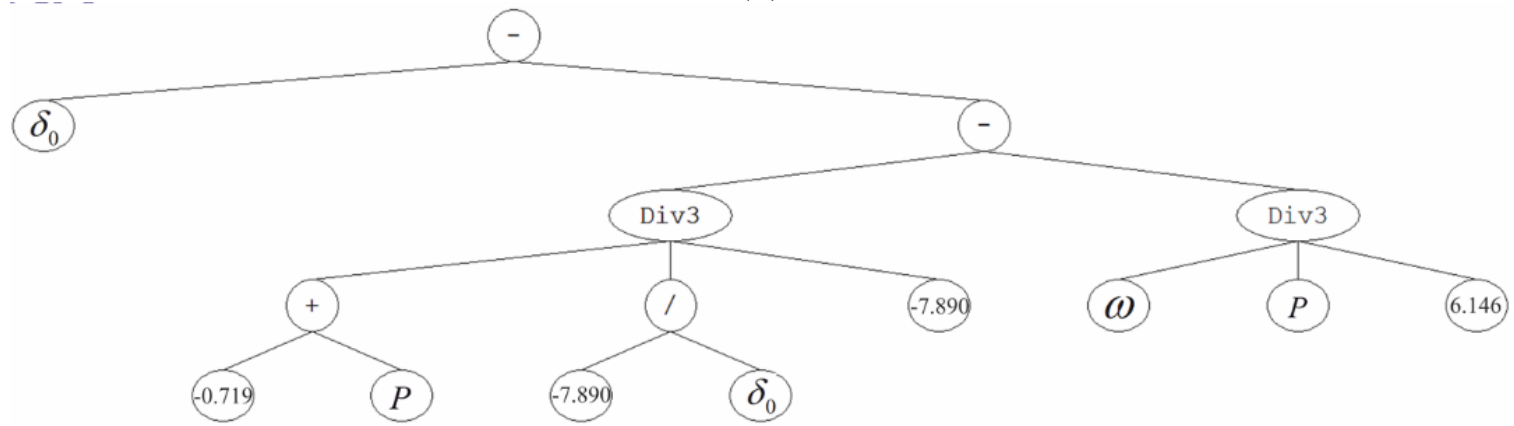

(b)

308 Figure 5. The best GEP model Tree representation for SBS modified bitumen a) Complex shear 309 modulus, b) Phase angle; Note: "6RT" and "Div3" are the $6^{\text {th }}$ root and triple division, respectively. 


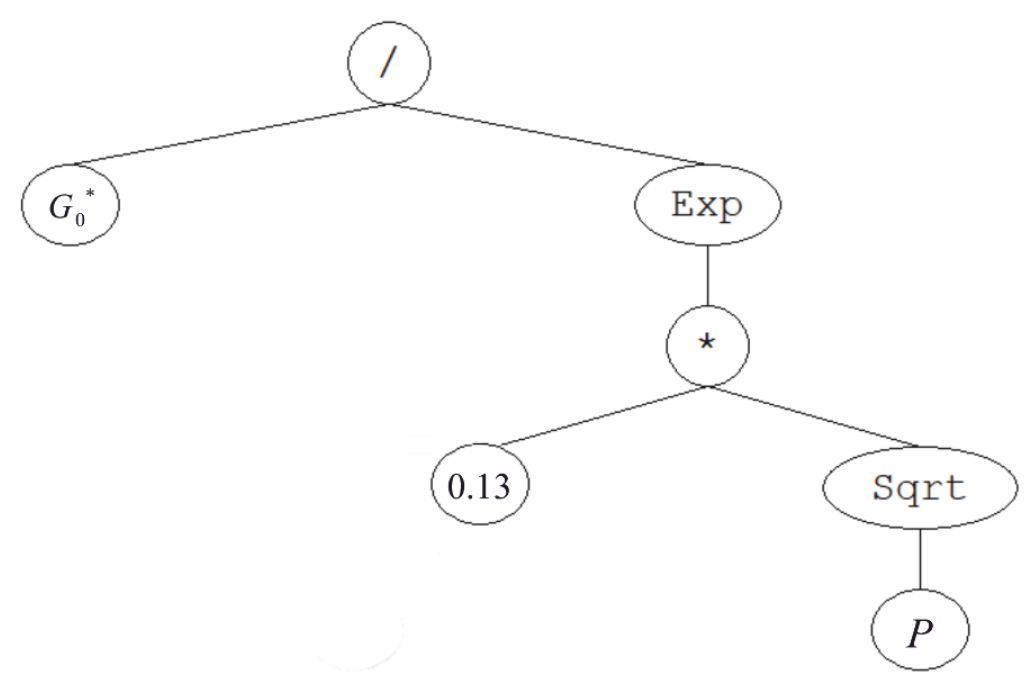

(a)

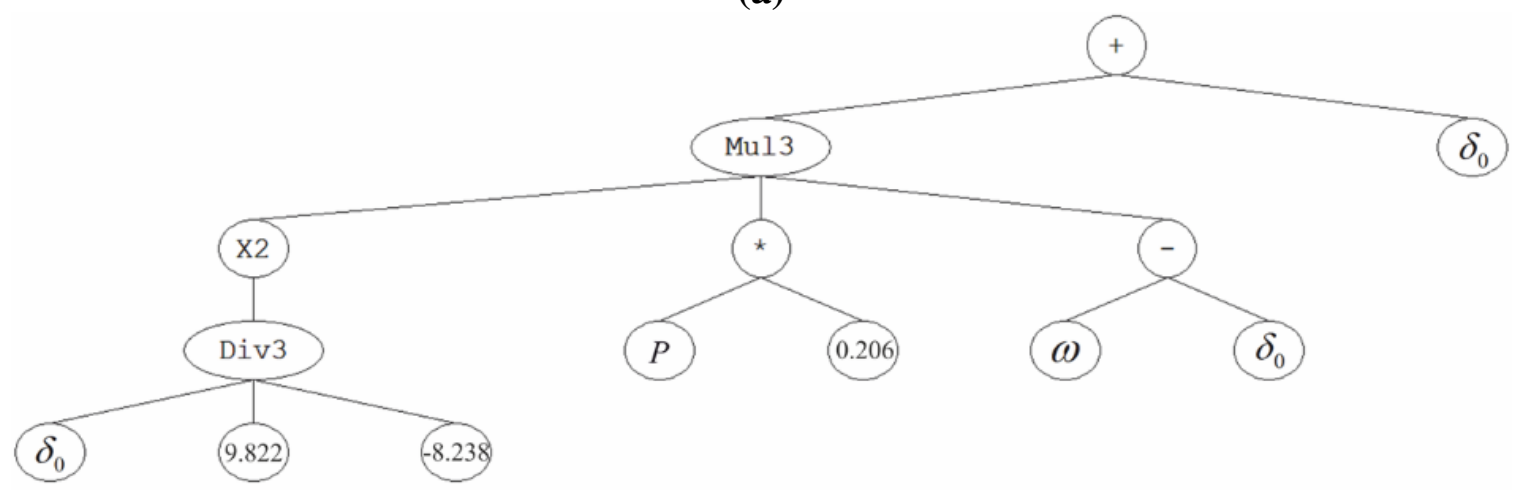

(b)

312 Figure 6. The best GEP model Tree representation for PPA modified bitumen a) Complex shear 313 modulus, b) Phase angle; Note: "Mul3" and "Div3" are the multiplication of three terms and triple division, respectively.

315 The formulations for the prediction of complex shear modulus and phase angle in the CR, SBS, 316 and PPA modified bitumen are as follow:

317 Crumb rubber modified bitumen:

$$
\begin{aligned}
& G^{*}=G_{0}{ }^{*} \cdot \exp \left(-\frac{P^{1.5}}{103.137}\right) \\
& \delta=\delta_{0}\left(1-\frac{P}{\omega+62}\right)+2.728
\end{aligned}
$$




$$
\begin{aligned}
& G^{*}=G_{0}^{*} \cdot \exp \left(-0.047 \times P^{5 / 6}\right) \\
& \delta=\delta_{0}+\frac{\omega}{6.146 P}-\frac{\delta_{0}(P-0.719)}{(7.89)^{2}}
\end{aligned}
$$

$$
\begin{aligned}
& G^{*}=G_{0}^{*} \cdot \exp \left(-0.13 \times P^{0.5}\right) \\
& \delta=\delta_{0}+3.149 \times 10^{-5} \times\left[\delta_{0}^{2} \cdot P \cdot\left(\omega-\delta_{0}\right)\right]
\end{aligned}
$$

323 Based on the experimental program, the ranges of validity of the proposed formulas (Eq. 7 9) are 324 as follows:

$$
\begin{aligned}
& 127 \mathrm{kPa} \leq \mathrm{G}_{0}^{*} \leq 523000 \mathrm{kPa} \\
& 9.39^{\circ} \leq \delta_{0} \leq 74^{\circ} \\
& 0.1 \mathrm{~Hz} \leq \omega \leq 100 \mathrm{~Hz} \\
& 10 \% \leq P_{C R} \leq 20 \% \\
& 2.0 \% \leq P_{S B S} \leq 6.0 \% \\
& 0.5 \% \leq P_{P P A} \leq 2.0 \%
\end{aligned}
$$

\section{Validity of the proposed models}

327 As per the recommendation by Frank and Todeschini [28], a model can be safely acceptable if the ratio of the number of data sets to the number of input parameters is greater than five. Here, the mentioned ratio for CR, SBS, and PPA modified bitumen are 88, 88, and 80, respectively, which indicates the validity of the number of data. Moreover, for a valid model, it is necessary for the

331 error value (e.g., RRMSE) to be at its minimum, and R to be higher than 0.8 [29]. In all of the selected prediction models, these statistical parameters were checked for the training and 
333 validation sets. A very good correlation between the predictions of the GP models and the 334 experimental data can be seen in the scatter diagrams (Figures 7 to 9). Meanwhile, for the external 335 validation of the proposed formulae on the verification dataset, the Golbraikh and Tropsha [30]

336 criteria were checked. This criterion suggests that at least one of the regression line slopes ( $k$ and $337 k^{\prime}$ ), which passes through the origin, should be close to one (i.e. $0.85<k, k^{\prime}<1.15$ ).

$$
\begin{aligned}
& k=\frac{1}{O^{2}} \sum O \times P \\
& k^{\prime}=\frac{1}{P^{2}} \sum O \times P
\end{aligned}
$$

338 where $O$ and $P$ are the experimental observations and GP predicted values, respectively. Table 6 339 presents the calculated validation criteria (Eq. 7) for GP models (Eq. 4, 5, and 6). According to 340 this table, all formulae met the criteria. Table 7 illustrates the calculated statistical indices from 341 Eq. 6 for all proposed formulae. Based on the $\mathrm{R}^{2}$, RRMSE, and PI values in this table, the results 342 of training and testing are very close, which shows that the models did not overfit.

Table 6. External validation of GEP models

\begin{tabular}{ccccc}
\cline { 2 - 5 } Additive & $G^{*}$ & $\delta$ & $G^{*}$ & $\delta$ \\
CR & 1.0017 & 1.0016 & 0.9828 & 0.9926 \\
SBS & 0.9957 & 1.0003 & 0.9884 & 0.9949 \\
PPA & 1.0013 & 0.9596 & 0.9902 & 1.0393 \\
\hline \multicolumn{3}{c}{$k$ and $k^{\prime}$ are regression line slopes }
\end{tabular}

344 Table 7. Statistical indices (Eq. 6) for the training and validation subsets of all formulae

\begin{tabular}{cccccccc}
\hline \multirow{2}{*}{ Additive } & \multirow{2}{*}{ Equation } & \multicolumn{3}{c}{ Training } & \multicolumn{3}{c}{ Validation } \\
\cline { 3 - 7 } & $\mathrm{R}^{2}$ & RRMSE $(\%)$ & $\mathrm{PI}$ & $\mathrm{R}^{2}$ & RRMSE $(\%)$ & PI \\
\hline \multirow{2}{*}{$\mathrm{CR}$} & $\delta$ & 0.974 & 19.4 & 0.098 & 0.971 & 18.2 & 0.091 \\
& $\delta$ & 0.974 & 7.0 & 0.035 & 0.973 & 8.5 & 0.043 \\
\multirow{2}{*}{ SBS } & $\mathrm{G}^{*}$ & 0.972 & 20.0 & 0.101 & 0.970 & 18.1 & 0.091 \\
& $\delta$ & 0.981 & 7.2 & 0.036 & 0.981 & 8.0 & 0.040 \\
\multirow{2}{*}{ PPA } & $\mathrm{G}^{*}$ & 0.990 & 13.2 & 0.066 & 0.985 & 13.9 & 0.070 \\
& $\delta$ & 0.956 & 8.5 & 0.043 & 0.974 & 7.0 & 0.035 \\
\hline
\end{tabular}




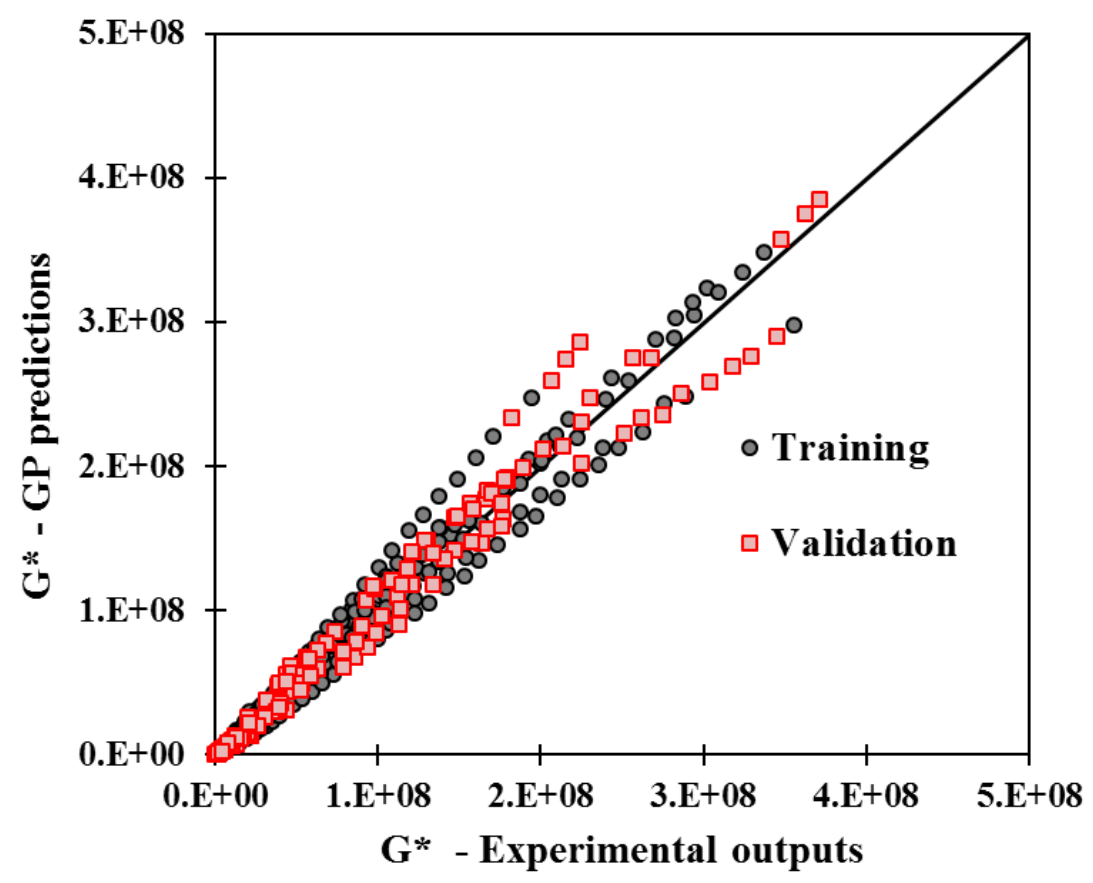

(a)

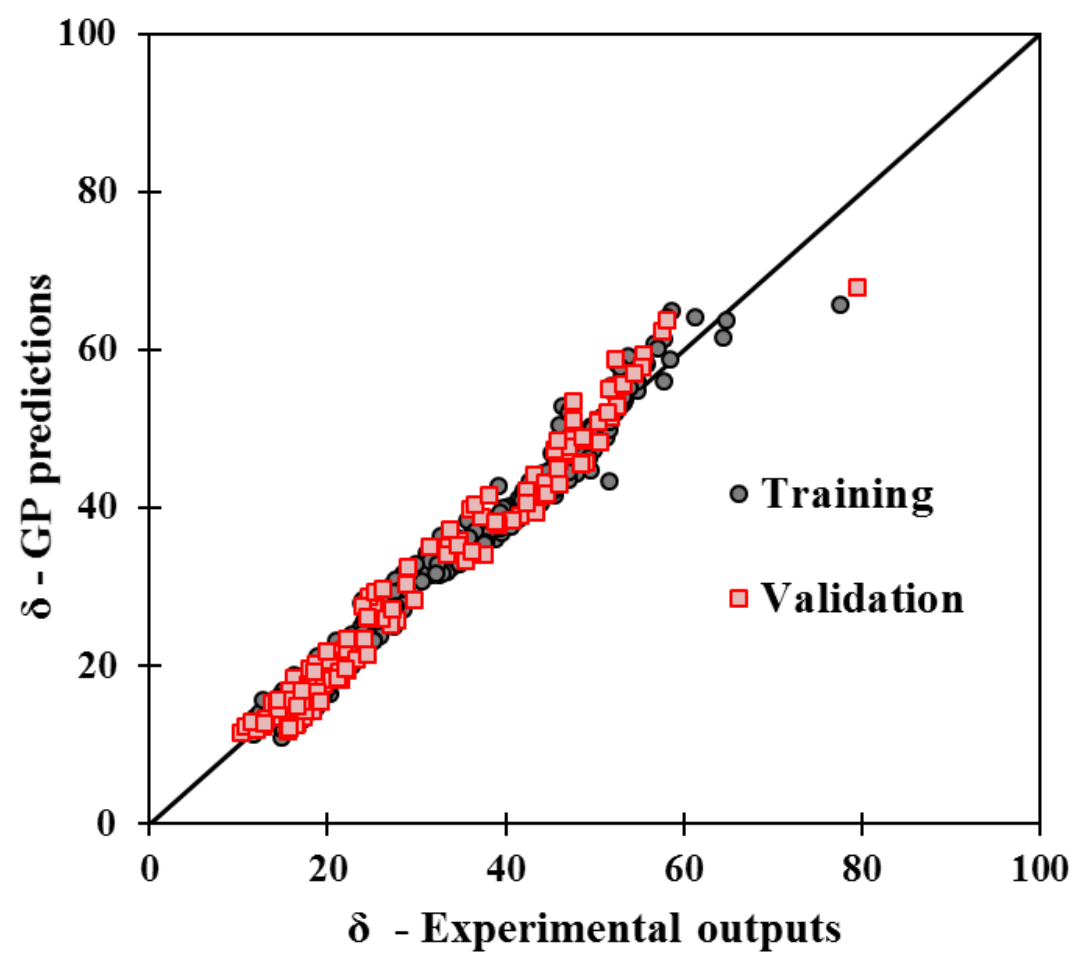

(b)

Figure 7. Experimental versus GEP model predictions for crumb rubber modified bitumen a) Complex shear modulus, b) Phase angle 


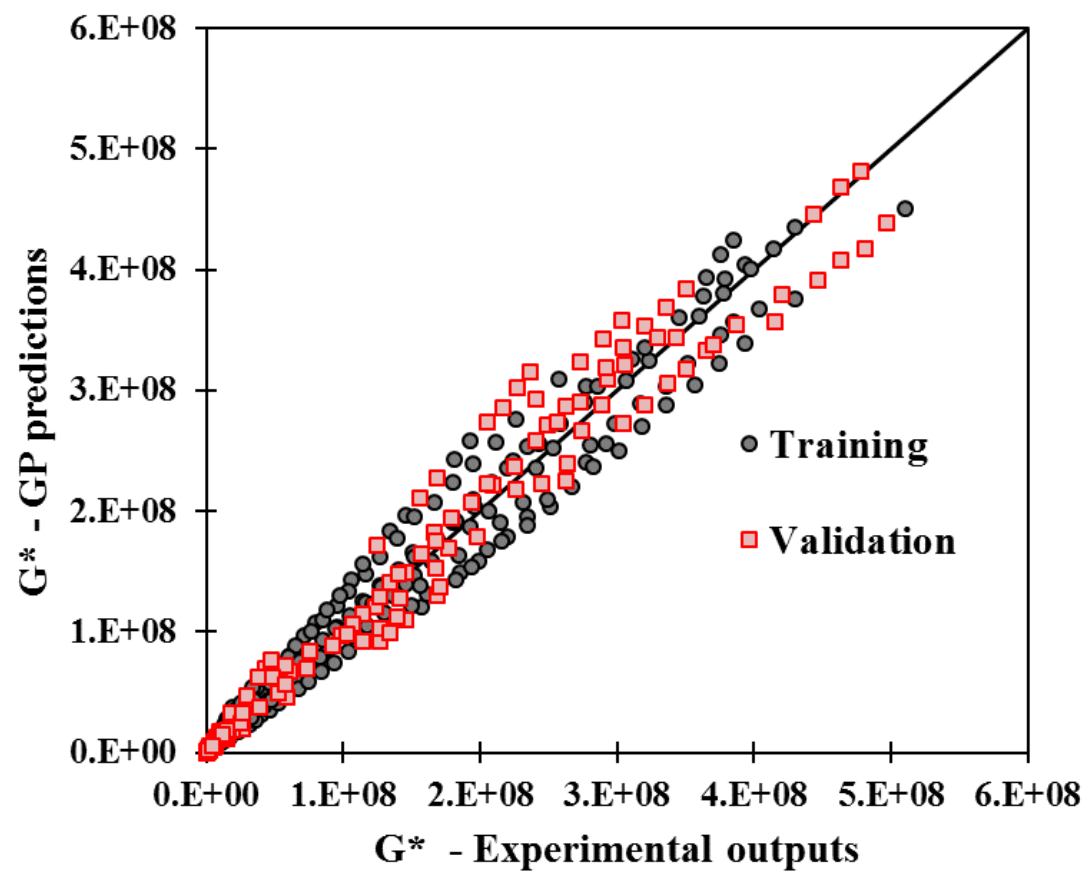

(a)

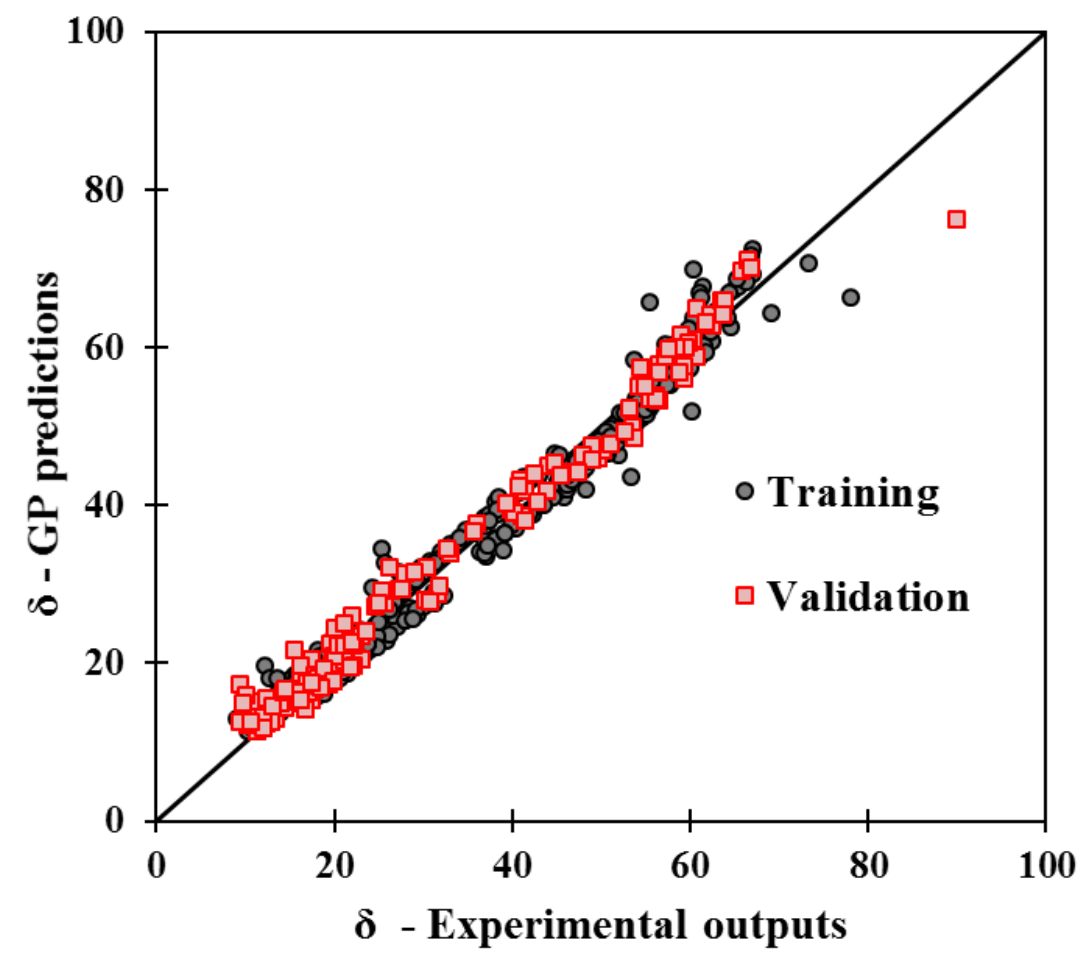

(b)

Figure 8. Experimental versus GEP model predictions for SBS modified bitumen a) Complex shear modulus, b) Phase angle 


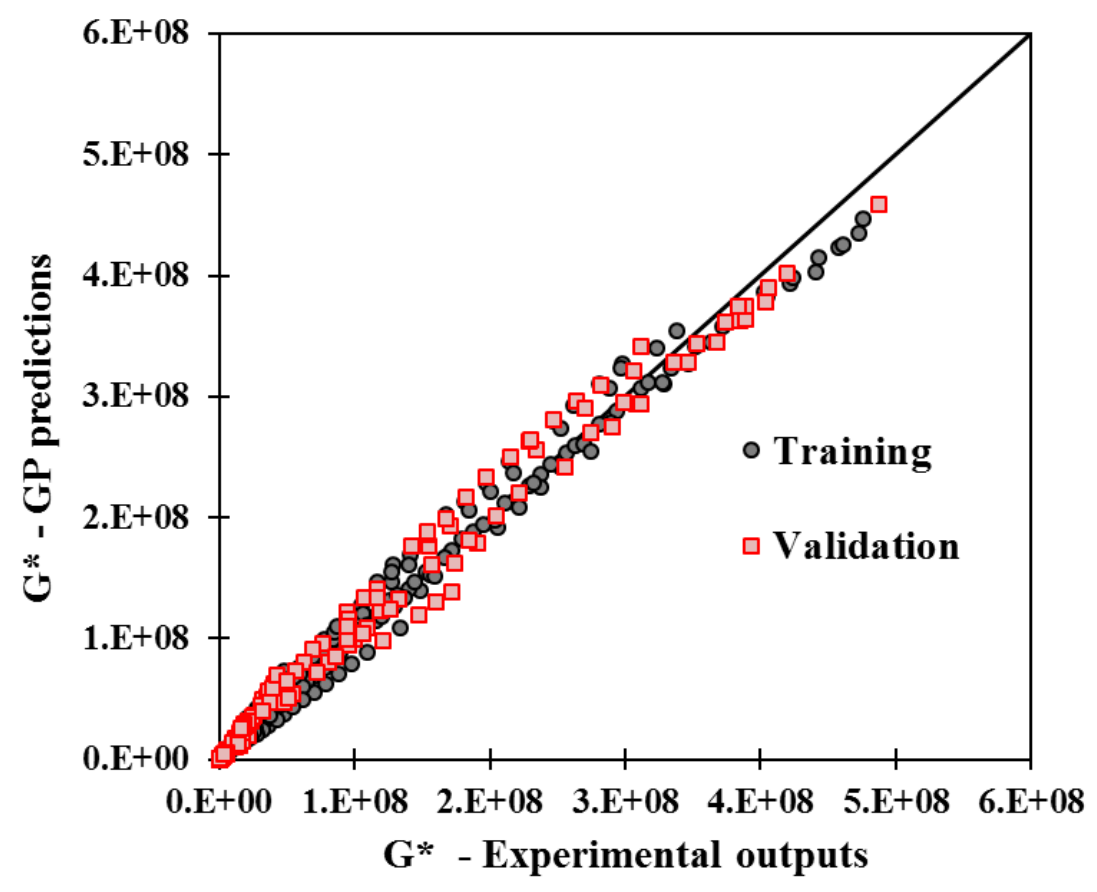

(a)

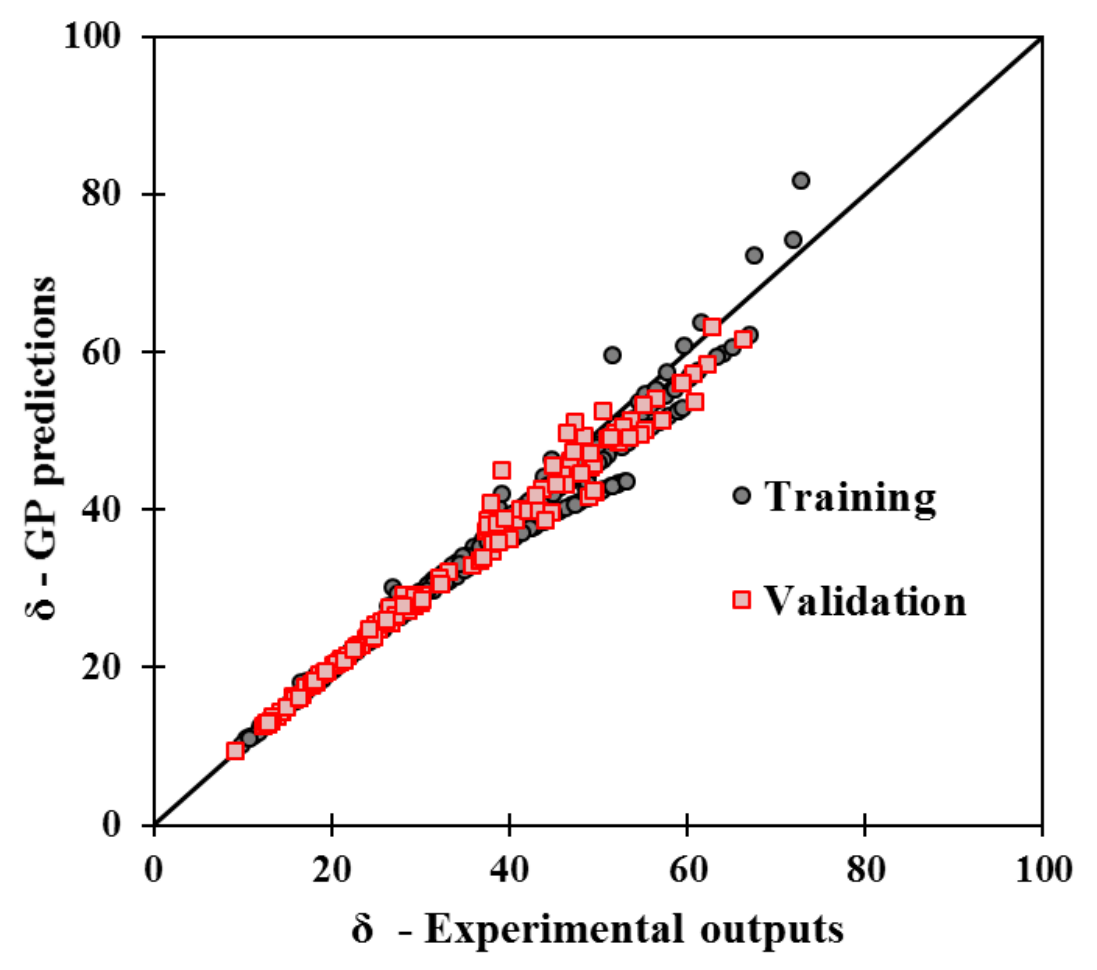

(b)

Figure 9. Experimental versus GEP model predictions for PPA modified bitumen a) Complex shear modulus, b) Phase angle 
349 An external validation analysis was conducted to examine the performance of the proposed 350 formulae on the prediction of the complex shear modulus and phase angle of the modified

351 bitumens. For this purpose, the experimental data from Hajikarimi et al. [31], Moghadas Nejad et 352 al. [32] and Samieadel and Fini [33] were used for the validation of the formulae on crumb rubber, 353 SBS and PPA-modified bitumens. The statistical parameters of the external data are presented in 354 Table 8. Scatter diagrams of the external validation study are illustrated in Table 9 and Figure 10 355 to 12 . According to the results, most of the data points are very close to the ideal correlation line. 356 Therefore, according to Table 9 and Figure 10 to 12, GEP models showed a very good performance 357 in the prediction of complex shear modulus and phase angle on the unseen experimental data.

Table 8. Statistics of input and output variables of the external data

\begin{tabular}{ccccccccc}
\hline Additive & Statistical Parameter & $\mathrm{T}\left({ }^{\circ} \mathrm{C}\right)$ & $\omega(\mathrm{Hz})$ & $\mathrm{G}_{0}(\mathrm{kPa})$ & $\delta_{0}(\mathrm{~s})$ & $\mathrm{P}(\%)$ & $\mathrm{G} *(\mathrm{kPa})$ & $\delta(\mathrm{s})$ \\
\hline \multirow{3}{*}{$\mathrm{CR}$} & Minimum & 10 & 0.1 & 17.555 & 35.4 & 5 & 7.375 & 34 \\
$(5,10,15,20 \%)$ & Maximum & 30 & 100 & 89300 & 85.4 & 20 & 80126 & 81 \\
& Mean & 20 & 16.4 & 13052 & 65.6 & 12.5 & 8558 & 56.7 \\
& Range & 20 & 99.9 & 89282 & 50.0 & 15 & 80119 & 47.5 \\
\hline SBS & Minimum & 10 & 0.1 & 21.0 & 35.7 & 2 & 17.0 & 35.4 \\
$(2,4,6 \%)$ & Maximum & 30 & 100 & 67303 & 80.9 & 6 & 61896 & 79.2 \\
& Mean & 20 & 16.4 & 9967801 & 60.3 & 4 & 8613 & 58.0 \\
& Range & 20 & 99.9 & 67282 & 45.2 & 4 & 61879 & 43.9 \\
\hline PPA & Minimum & 20 & 0.1 & 819.5 & 26.5 & 1.0 & 719.6 & 27.9 \\
$(1 \%)$ & Maximum & 20 & 101.4 & 26253 & 72.8 & 1.0 & 23052 & 60.7 \\
& Mean & 20 & 15.6 & 9670 & 46.9 & 1.0 & 8491 & 43.7 \\
& Range & 0 & 101.3 & 25433 & 46.3 & 0.0 & 22333 & 32.8 \\
\hline
\end{tabular}

* The base binder was PG58-22

Table 9. Statistical indices (Eq. 6) for the prediction of all formula on the external datasets

\begin{tabular}{ccccc}
\hline \multirow{2}{*}{ Additive } & Equation & $\mathrm{R}^{2}$ & RRMSE (\%) & PI \\
\hline \multirow{2}{*}{$\mathrm{CR}$} & $\mathrm{G}^{*}$ & 0.9911 & 0.1646 & 0.08 \\
& $\delta$ & 0.8576 & 0.1706 & 0.09 \\
\multirow{2}{*}{$\mathrm{SBS}$} & $\mathrm{G}^{*}$ & 0.9675 & 0.3036 & 0.15 \\
& $\delta$ & 0.8848 & 0.1193 & 0.06 \\
\multirow{2}{*}{ PPA } & $\mathrm{G}^{*}$ & 0.9966 & 0.1722 & 0.09 \\
& $\delta$ & 0.9685 & 0.1215 & 0.06 \\
\hline
\end{tabular}




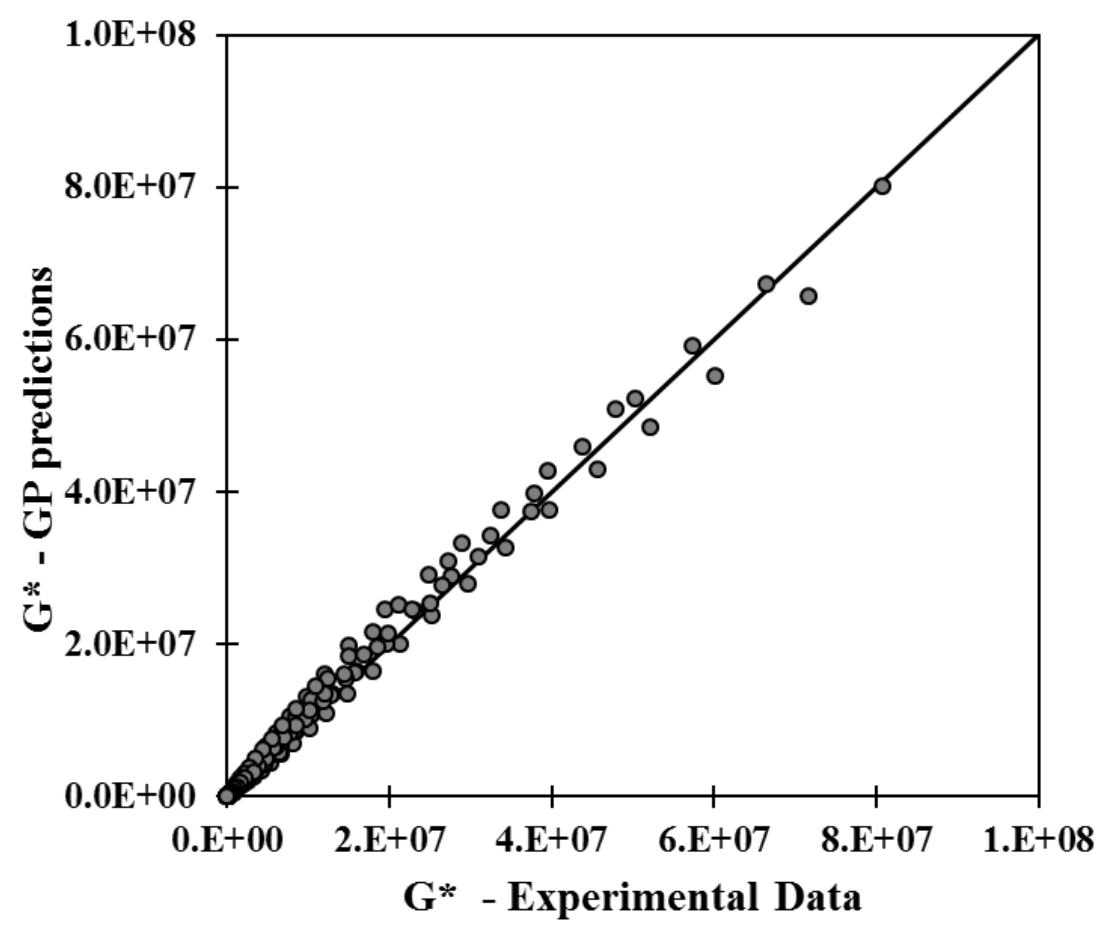

(a)

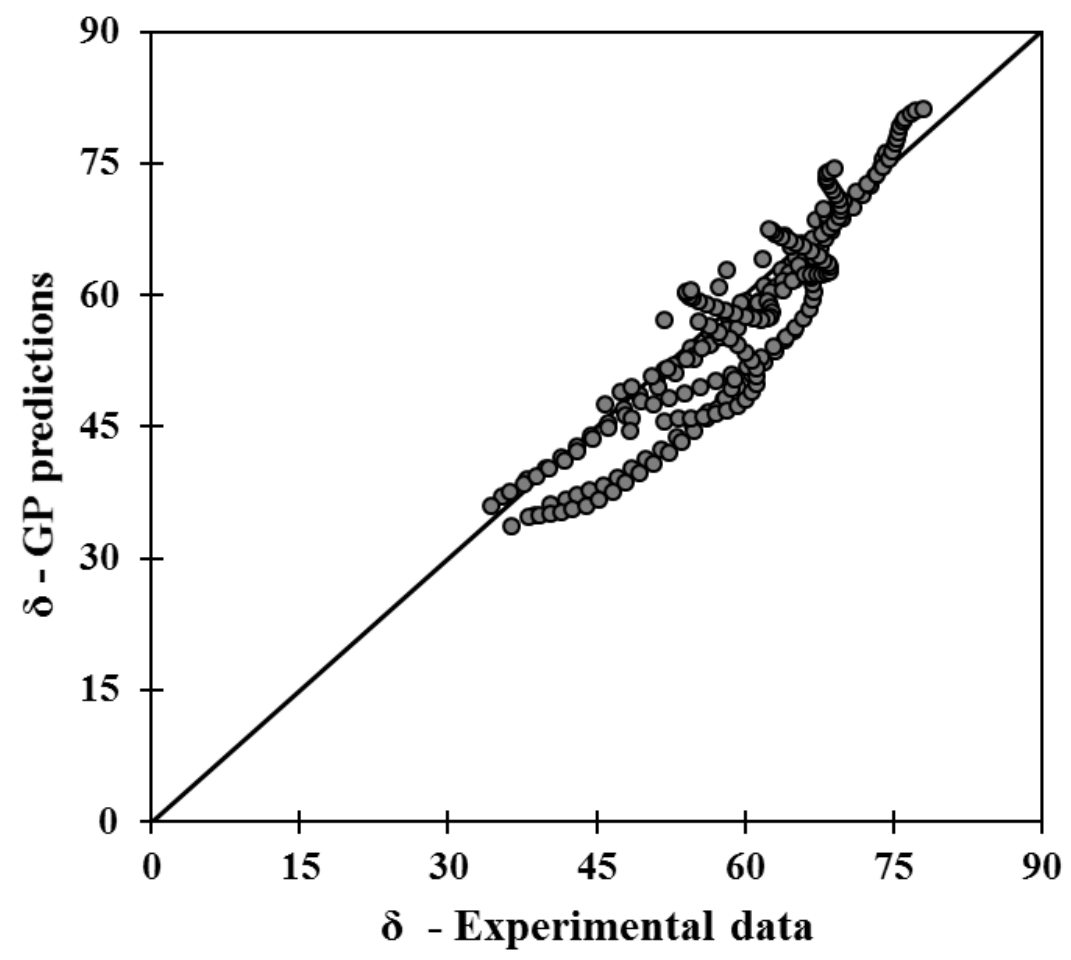

(b)

Figure 10. Experimental external data versus GEP model predictions for crumb rubber modified bitumen a) complex shear modulus, b) phase angle 


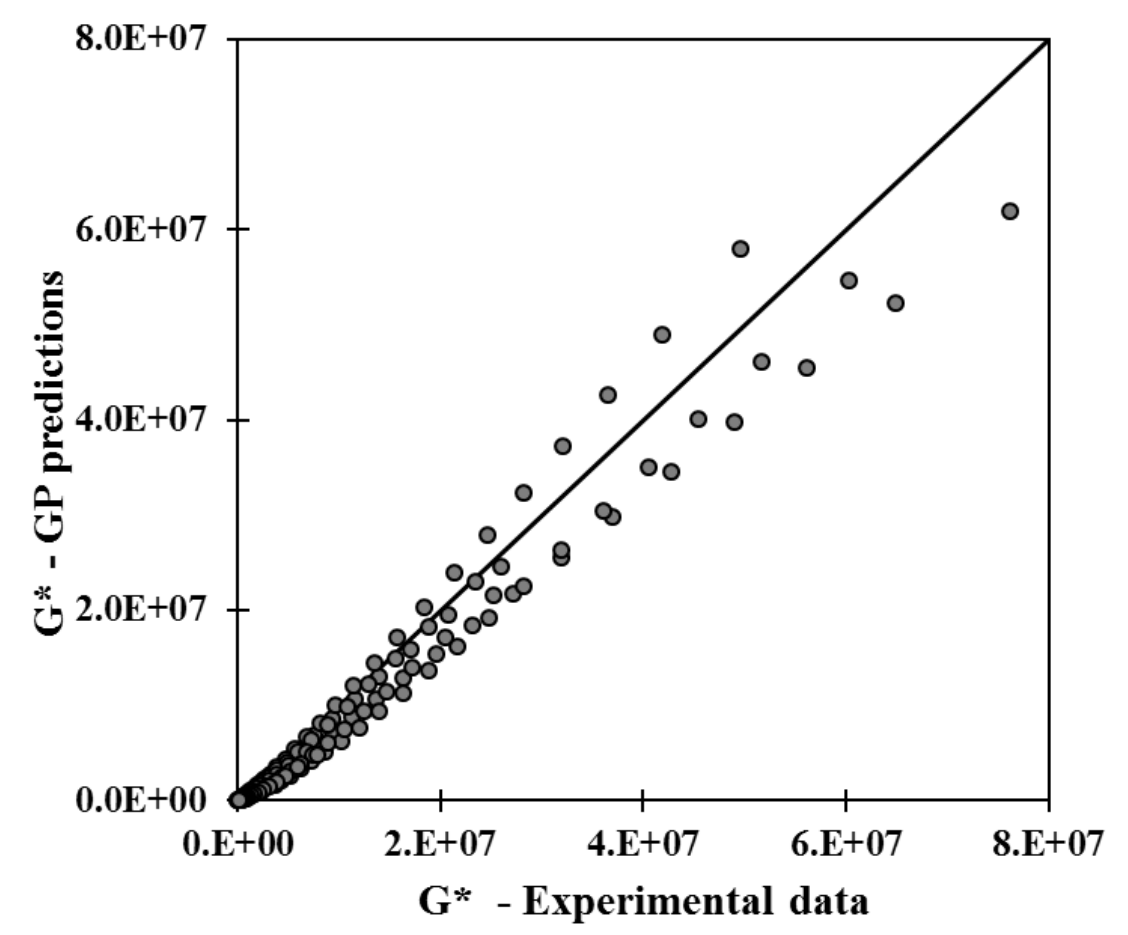

(a)

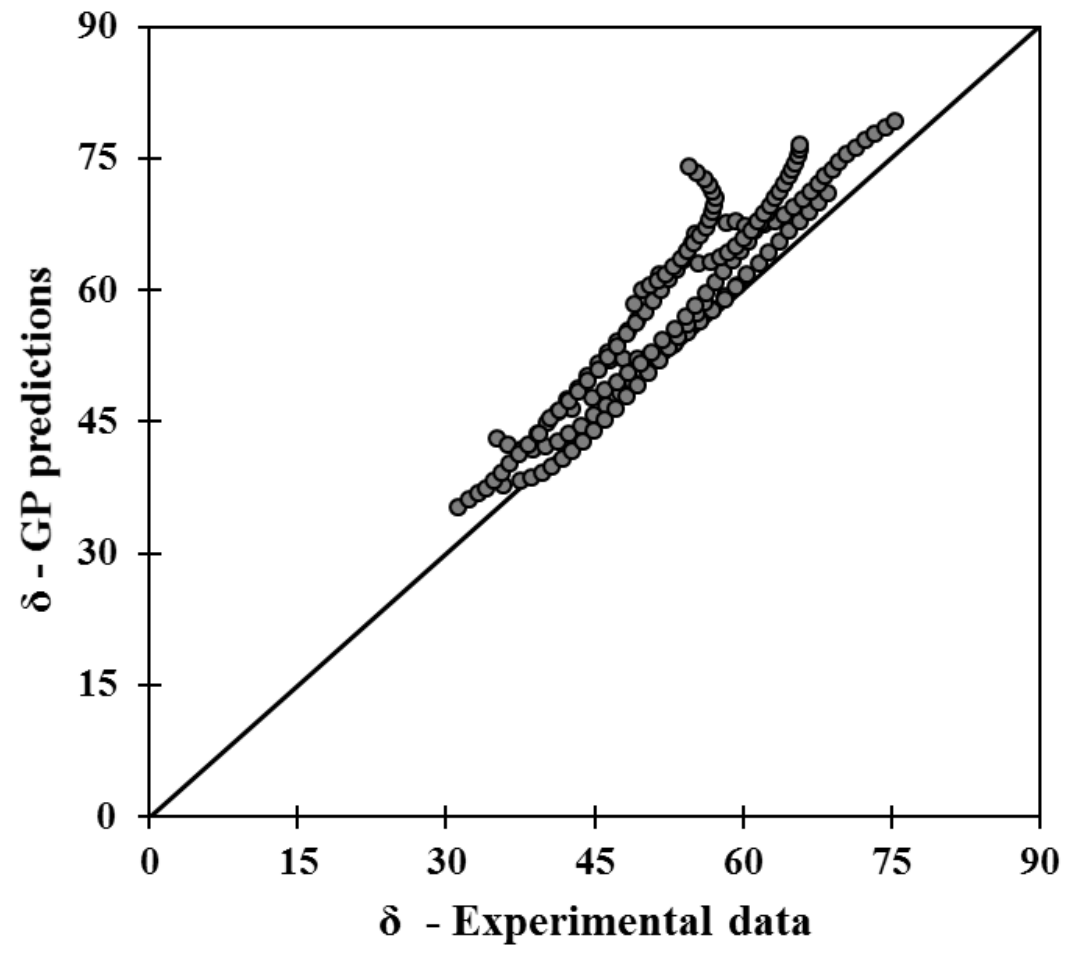

(b)

Figure 11. Experimental external data versus GEP model predictions for SBS modified bitumen a) complex shear modulus, b) phase angle 


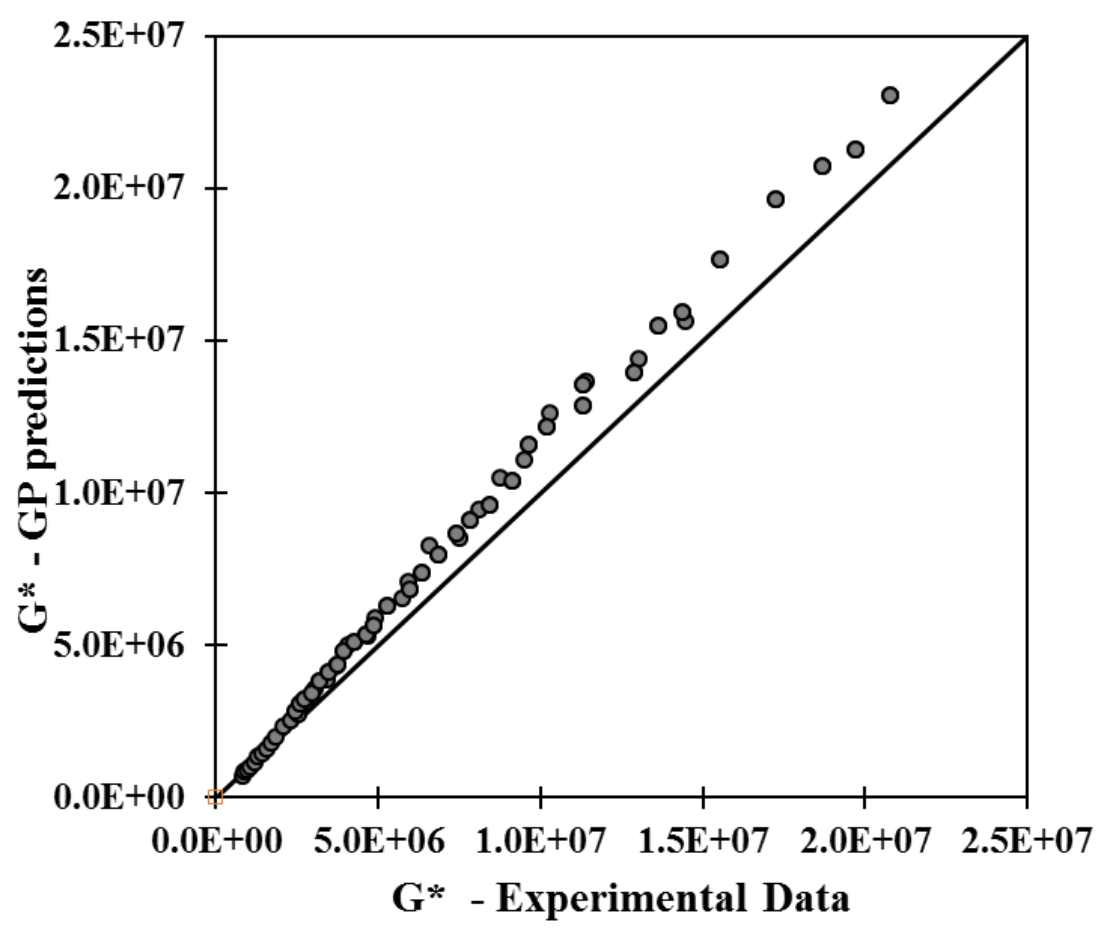

(a)

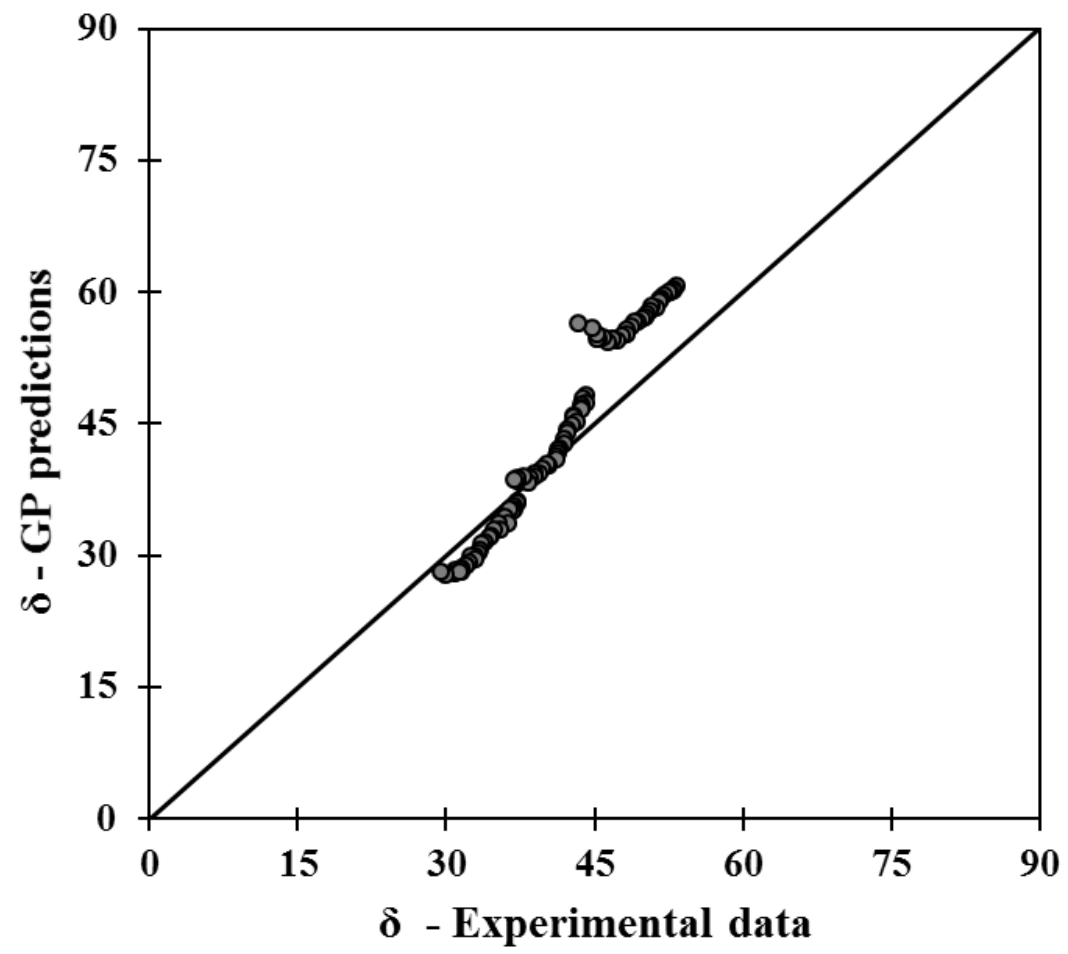

(b)

Figure 12. Experimental external data versus GEP model predictions for PPA modified bitumen a) complex shear modulus, b) phase angle 


\section{Parametric study and sensitivity analysis}

A parametric study of the GEP models was conducted to examine the robustness of the prediction models for all three modified bitumens, and the response of each GEP model to its corresponding input parameters was investigated. The three-dimensional diagrams in Figures 13 to 17 illustrate the general trend of the models against pairs of input predictors for the presented formulae for CR, SBS, and PPA modified bitumens. As can be seen in Figures 13 to 15, the observed trends were in good agreement with the structure of the proposed formulae. For example, the increasing effect of complex shear modulus and phase angle on the base bitumen is obvious, and it can be seen that a higher percentage of modifier decreased the modified complex shear modulus. This effect can be clearly observed in Figure 13-a as well as in Figure 14-a and Figure 15-a. Figure 13-b, Figure 14$\mathrm{b}$, and Figure 15-b show that with an average additive percentage, the higher the loading frequency that is applied on the specimen, the sharper the effectiveness of the phase angle of unmodified bitumen. Meanwhile, the decreasing effect of additive percentage together with the boosting influence of phase angle of the original bitumen on the phase angle of the modified bitumen can be clearly seen in Figure 13-c, Figure 14-c, and Figure 15-c. Based on Figure 13-d, Figure 14-d, and Figure 15-d, which provide a better understanding of the influence of additive percentage and loading frequency: increasing the loading frequency enhanced the phase angle of the modified bitumen; however; this effect was stronger for crumb rubber additive as compared to the other additives. It can be observed in Figure 13-d that increasing the percentage of the modifier decreased the phase angle of the modified bitumen, and this effect increased in lower frequencies. Nevertheless, Figure 14-d shows that increasing the loading frequency intensified the decreasing effect of the percentage of SBS. Both crumb rubber and SBS increased the stiffness and viscosity of bitumen which resulted in increasing of the elastic characteristics of modified bitumen. A rather different behavior was observed for the PPA modifier against the loading frequency. As shown in 
384 Figure 15-d, increasing the loading frequency changed the decreasing effect of the PPA modifier 385 to an increasing effect. It is reported that adding PPA disturbs the hydrogen-bond network 386 formation in bitumen which results in reduction of the effective molecular weight of asphaltenes 387 accumulated through hydrogen bonds and disruption of the asphaltenes-maltenes equilibrium 388 which can result in such a rheological behavior [34]. It is necessary to mention that the effect of 389 PPA directly depends on the amount of wax and asphaltene of the original bitumen [20]. Overall, 390 the parametric study confirmed that the prediction models (e.g., proposed equations) are capable 391 of capturing the characteristics of the effective input parameters. 


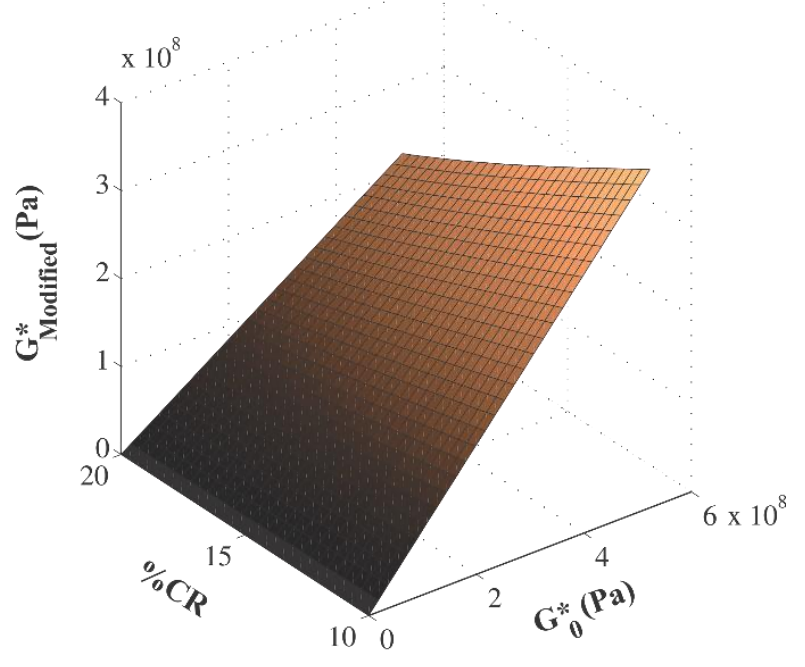

(a)

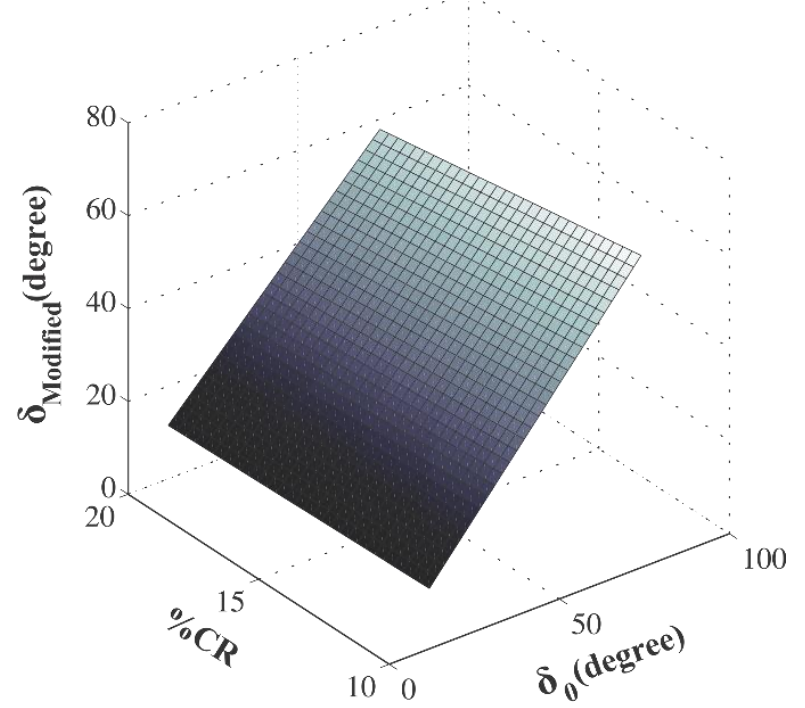

(c)

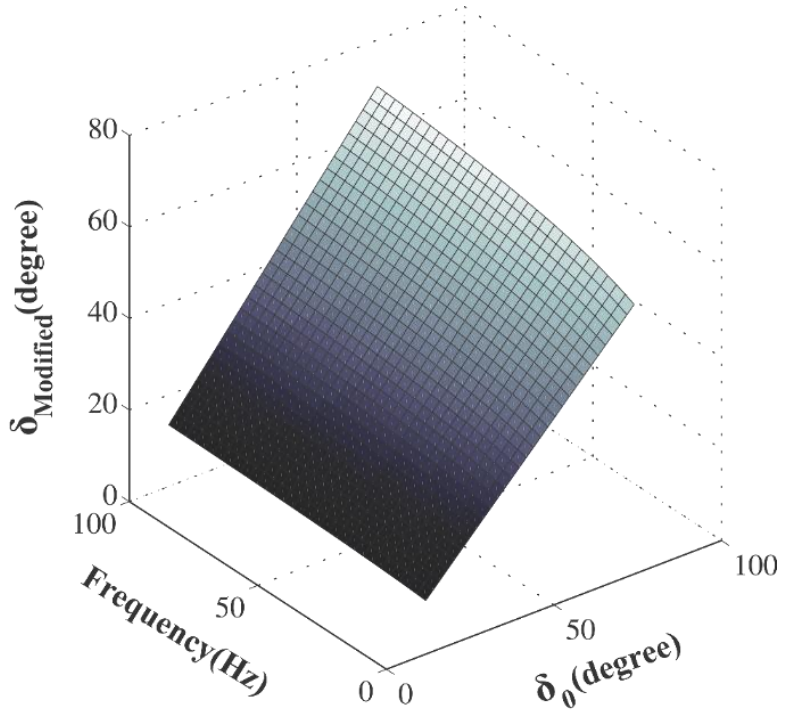

(b)

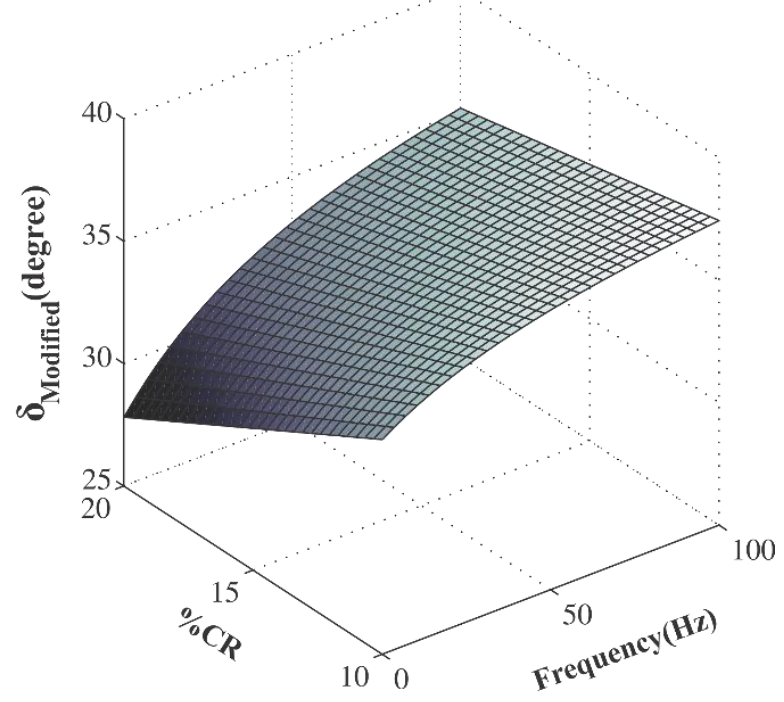

(d)

Figure 13. Parametric study of CR-modified bitumen viscoelastic behavior inputs and target parameters in the GEP models. a) Complex shear modulus in modified bitumen vs. unmodified bitumen and additive percentage, $b$ ) phase angle in modified bitumen vs. unmodified bitumen and loading frequency, c) phase angle in modified bitumen vs. unmodified bitumen and additive percentage, $\mathrm{d}$ ) phase angle in modified bitumen vs. loading frequency and additive percentage 


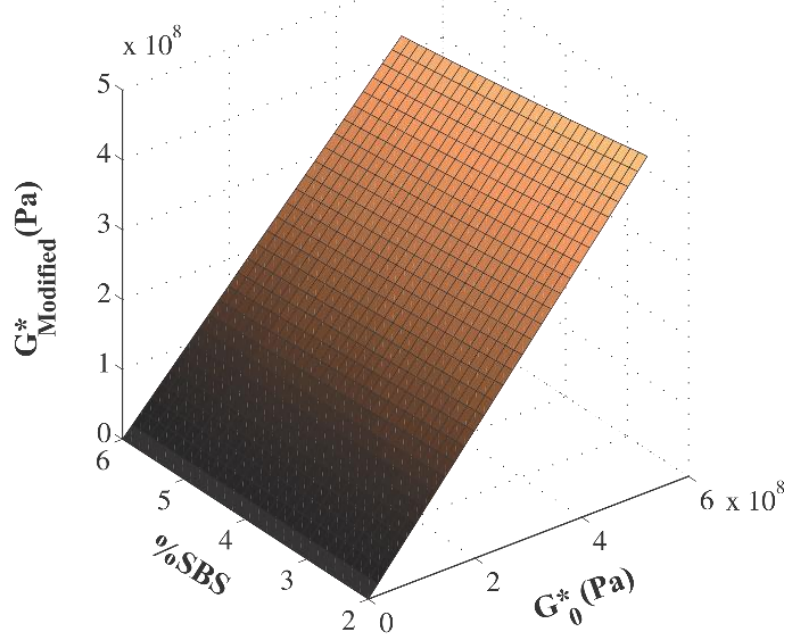

(a)

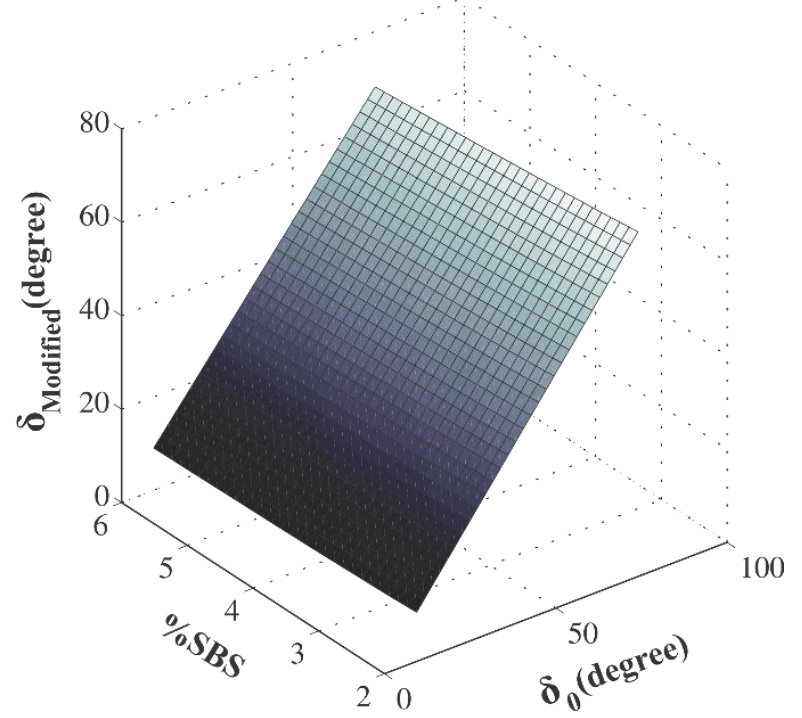

(c)

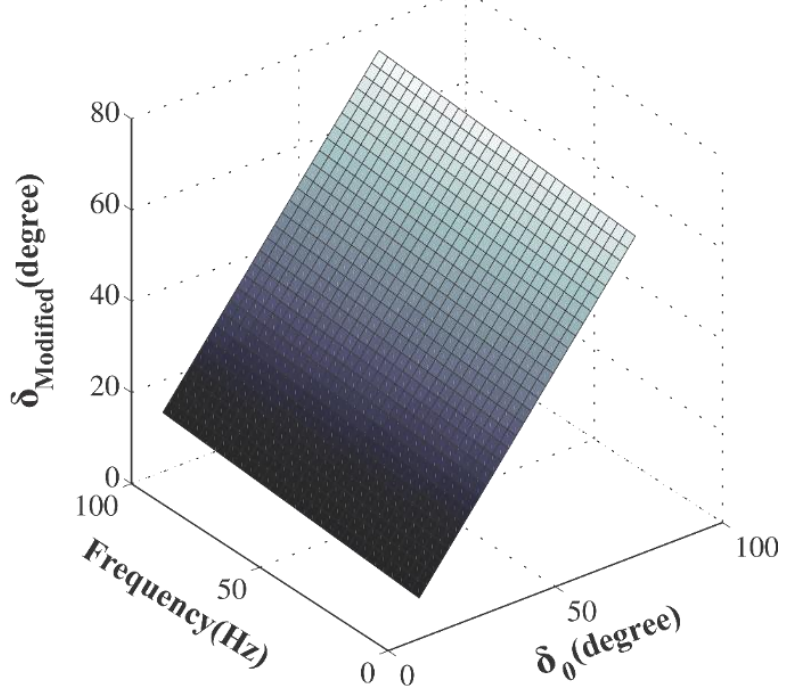

(b)

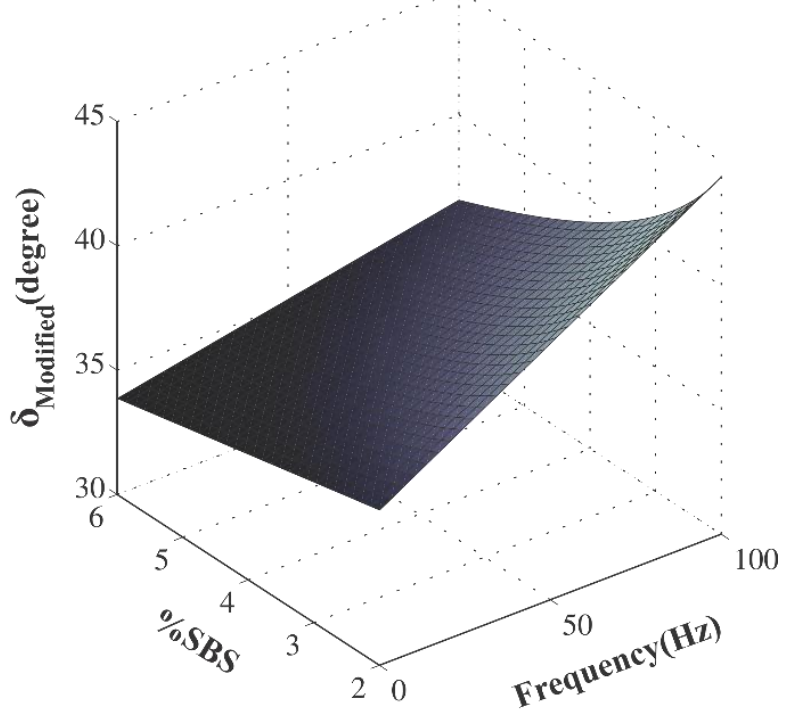

(d)

Figure 14. Parametric study of SBS-modified bitumen viscoelastic behavior inputs and target parameters in the GEP models. a) Complex shear modulus in modified bitumen vs. unmodified bitumen and additive percentage, b) phase angle in modified bitumen vs. unmodified bitumen and loading frequency, c) phase angle in modified bitumen vs. unmodified bitumen and additive percentage, $\mathrm{d}$ ) phase angle in modified bitumen vs. loading frequency and additive percentage 


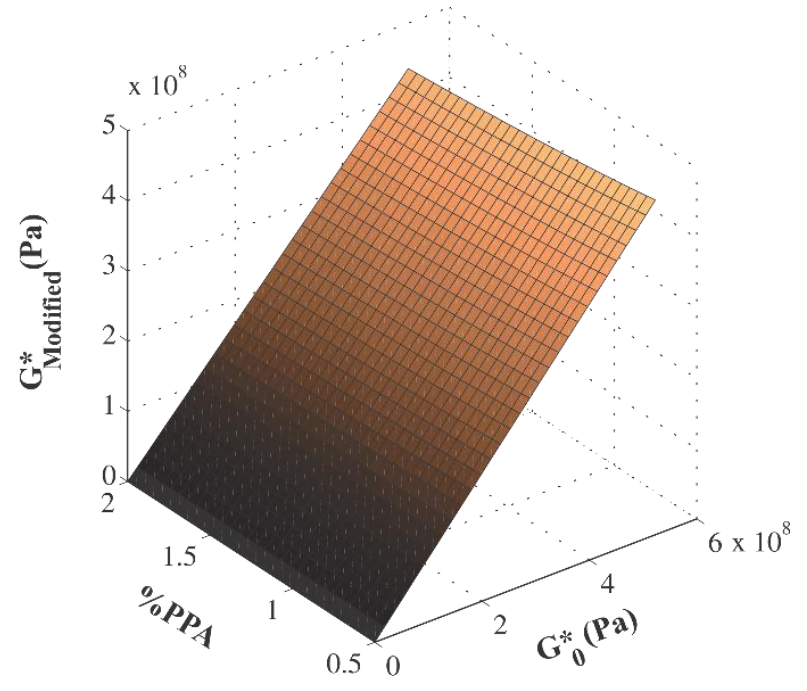

(a)

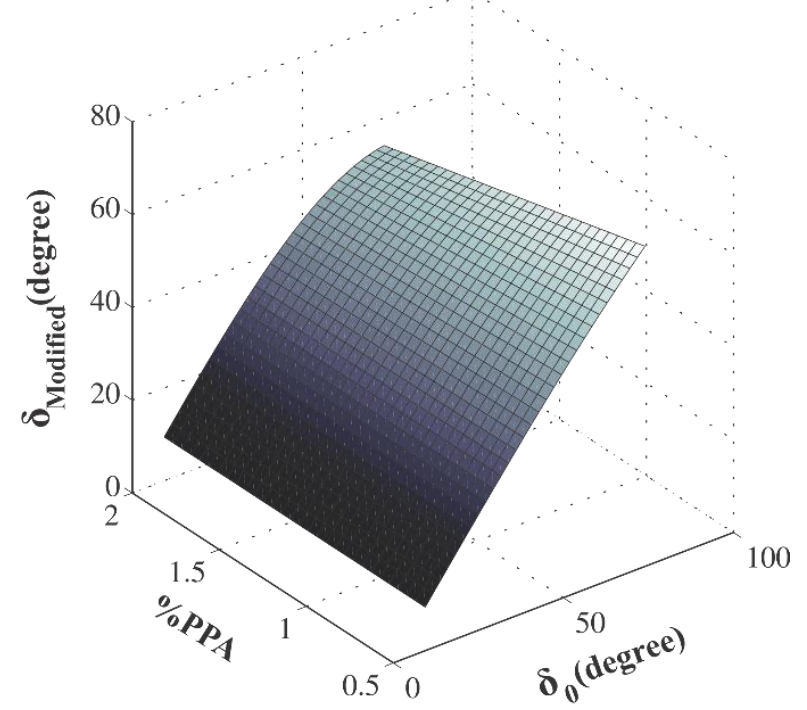

(c)

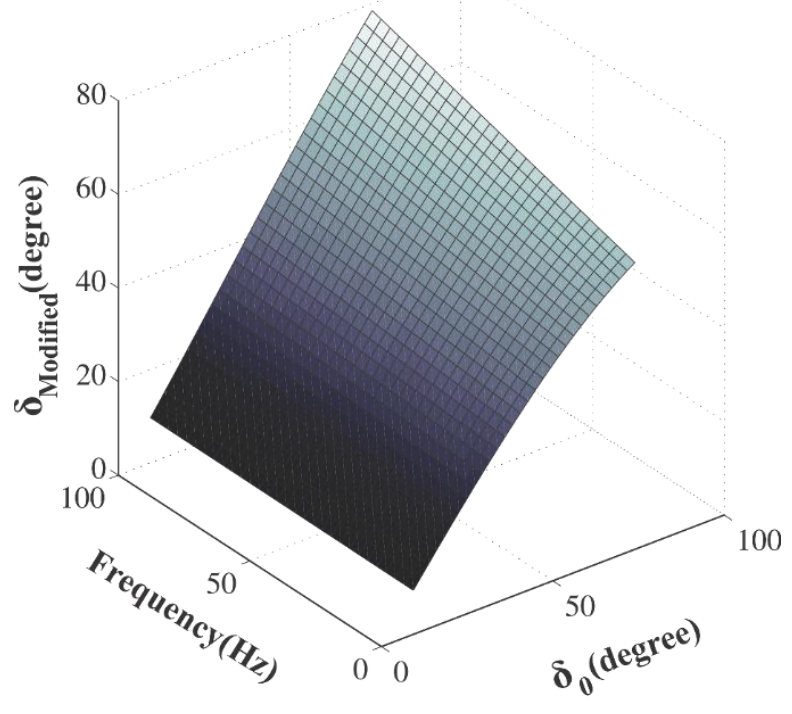

(b)

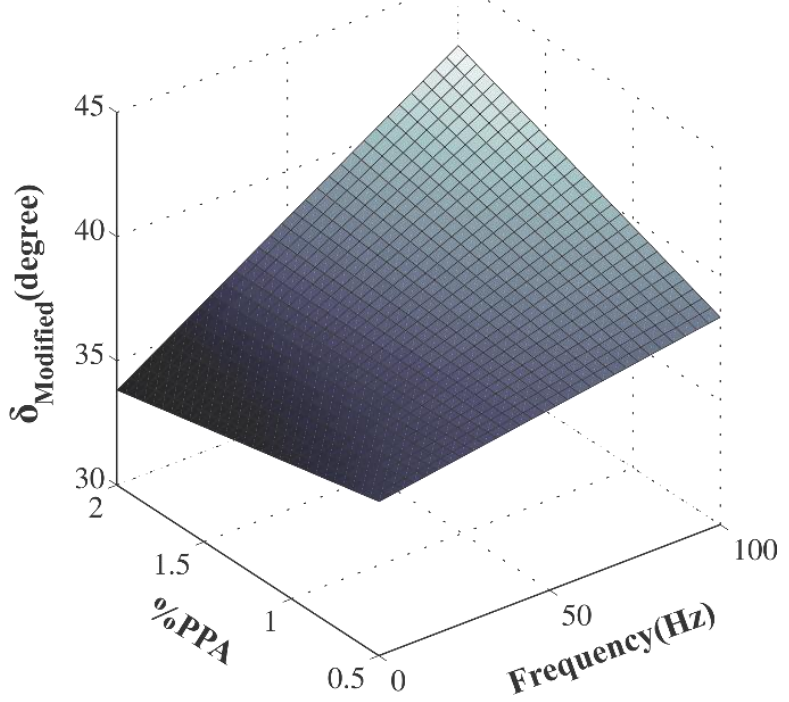

(d)

Figure 15. Parametric study of PPA-modified bitumen viscoelastic behavior inputs and target parameters in the GEP models. a) Complex shear modulus in modified bitumen vs. unmodified bitumen and additive percentage, b) phase angle in modified bitumen vs. unmodified bitumen and loading frequency, c) phase angle in modified bitumen vs. unmodified bitumen and additive percentage, $d$ ) phase angle in modified bitumen vs. loading frequency and additive percentage

397 The contribution rate of each input parameter was examined by sensitivity analysis. For this, the sensitivity percentage of each output parameter to each contributing input parameter was 399 calculated using the following formulae [35]. 


$$
\begin{aligned}
& D_{i}=f_{\text {max }}\left(v_{i}\right)-f_{\text {min }}\left(v_{i}\right) \\
& S_{i}=\frac{D_{i}}{\sum D} \times 100
\end{aligned}
$$

400

401

402

403

404

405

406

407

408

409

410

411

412

413

414

415

416

417 robustness of the formulae were investigated using various statistical indices for error calculation models

\begin{tabular}{cccccc}
\hline \multirow{2}{*}{ Formula } & \multirow{2}{*}{ Additive } & \multicolumn{5}{c}{ Input parameter } \\
& & $G_{0}{ }^{*}$ & $\delta_{0}$ & $\omega$ & $\mathrm{P}$ \\
\hline \multirow{2}{*}{$\mathrm{G}^{*}$} & $\mathrm{CR}$ & 88.8 & - & - & 11.2 \\
& $\mathrm{SBS}$ & 96.7 & - & - & 3.3 \\
& $\mathrm{PPA}$ & 98 & - & - & 2 \\
\hline \multirow{2}{*}{$\delta$} & $\mathrm{CR}$ & - & 83.6 & 8.8 & 7.6 \\
& $\mathrm{SBS}$ & - & 89.3 & 5.9 & 4.8 \\
& $\mathrm{PPA}$ & - & 88 & 9.3 & 2.7 \\
\hline
\end{tabular}

\section{Summary and Conclusion}

GEP, which is a robust and natural development of traditional GP, was used to develop formulae that can be used to predict the complex shear modulus and phase angle of modified asphalt bitumen. The input data consisted of results of an experimental program conducted on three different additives, namely crumb rubber, SBS, and PPA. It is necessary to mention that all experiments were performed at a low strain amplitude $(0.01 \%)$, and consequently, all derived equations are valid for the linear viscoelastic behavior of modified bitumens. The validity and 
418 and other well-known criteria. Also, an external validation analysis was conducted in order to 419 examine the performance of the proposed formulae against an unseen set of data. Moreover, a 420 parametric study was performed that investigated the effect of each input parameter on model 421 predictions and, through a sensitivity analysis, the level of dependency of the output parameters

422 on each of the inputs was studied. It was generally found that the complex shear modulus and 423 phase angle of modified bitumen were dependent mainly on the viscoelastic parameters of the 424 original bitumen, rather than other parameters. Also, to provide additional insight into the 425 meaningfulness of the derived formulae, results of the parametric study that evaluated the effect 426 of the corresponding input variables on the target parameters were presented in the form of three427 dimensional surface diagrams. These relationships were interpreted and compared with the 428 experimental trends, which showed that the trend of GEP formulation is consistent with the 429 material behavior observed in the tests.

\section{8. Future Research Work}

432 This research work presented a GEP model that can be used to predict complex shear modulus $433\left(\mathrm{G}^{*}\right)$ and phase angle $(\delta)$ as two constitutive parameters of bitumen modified with crumb rubber, 434 SBS, and PPA, and three closed-form equations were derived for these additives. However, two 435 main issues should be considered for future research works: 1) using original bitumens from 436 different sources, and 2) running experiments under different test conditions. Original bitumens 437 from different sources can be used to incorporate additional parameters into the prediction model; 438 e.g., asphaltene or maltene content. Additionally, it is possible to run frequency sweep tests at 439 temperatures higher than $22^{\circ} \mathrm{C}$ and applying strain that is greater than $0.01 \%$ in order to involve 
more testing conditions for predicting modified bitumen characteristics over a wide range of temperature and loading rates.

\section{References}

[1] S. Aflaki and N. Tabatabaee, "Proposals for modification of Iranian bitumen to meet the climatic requirements of Iran," Constr. Build. Mater., vol. 23, no. 6, pp. 2141-2150, 2009, doi: https://doi.org/10.1016/j.conbuildmat.2008.12.014.

[2] Y. Yildirim, "Polymer modified asphalt binders," Constr. Build. Mater., vol. 21, no. 1, pp. 66-72, 2007, doi: https://doi.org/10.1016/j.conbuildmat.2005.07.007.

[3] K. B. Vural, Y. Mehmet, and G. Alaaddin, "Evaluation of Low-Temperature and Elastic Properties of Crumb Rubber- and SBS-Modified Bitumen and Mixtures," J. Mater. Civ. Eng., vol. 25, no. 2, pp. 257-265, Feb. 2013, doi: 10.1061/(ASCE)MT.19435533.0000590 .

[4] A. H. Gandomi, S. K. Babanajad, A. H. Alavi, and Y. Farnam, "Novel approach to strength modeling of concrete under triaxial compression," J. Mater. Civ. Eng., vol. 24, no. 9, pp. 1132-1143, 2012.

[5] C. Ferreira, "Gene expression programming: a new adaptive algorithm for solving problems," arXiv Prepr. cs/0102027, 2001.

[6] A. H. Gandomi, A. H. Alavi, and C. Ryan, Handbook of genetic programming applications. Springer, 2015.

[7] A. Gholampour, A. H. Gandomi, and T. Ozbakkaloglu, "New formulations for mechanical properties of recycled aggregate concrete using gene expression programming," Constr.

Build. Mater., vol. 130, pp. 122-145, 2017, doi: https://doi.org/10.1016/j.conbuildmat.2016.10.114.

[8] J. Liu, K. Yan, L. You, P. Liu, and K. Yan, "Prediction models of mixtures' dynamic modulus using gene expression programming," Int. J. Pavement Eng., vol. 18, no. 11, pp. 971-980, Nov. 2017, doi: 10.1080/10298436.2016.1138113.

[9] A. Eleyedath and A. K. Swamy, "Prediction of density and viscosity of bitumen," Pet. Sci. Technol., vol. 36, no. 21, pp. 1779-1786, 2018.

[10] A. R. Azarhoosh, Z. Zojaji, and F. Moghadas Nejad, "Nonlinear genetic-base models for prediction of fatigue life of modified asphalt mixtures by precipitated calcium carbonate," Road Mater. Pavement Des., vol. 21, no. 3, pp. 850-866, 2020.

[11] B. V. Kok, M. Yilmaz, B. Sengoz, A. Sengur, and E. Avci, "Investigation of complex modulus of base and SBS modified bitumen with artificial neural networks," Expert Syst. Appl., vol. 37, no. 12, pp. 7775-7780, 2010, doi: https://doi.org/10.1016/j.eswa.2010.04.063. 
[12] N. I. M. Yusoff, D. Ibrahim Alhamali, A. N. H. Ibrahim, S. A. P. Rosyidi, and N. Abdul Hassan, "Engineering characteristics of nanosilica/polymer-modified bitumen and predicting their rheological properties using multilayer perceptron neural network model," Constr. Build. Mater., vol. 204, pp. 781-799, 2019, doi: https://doi.org/10.1016/j.conbuildmat.2019.01.203.

[13] S. Han, Z. Zhang, Y. Yuan, and K. Wang, "Prediction of asphalt complex viscosity by artificial neural network based on Fourier transform infrared spectroscopy," Pet. Sci. Technol., vol. 37, no. 14, pp. 1731-1737, Jul. 2019, doi: 10.1080/10916466.2019.1605377.

[14] D. Lo Presti, "Recycled tyre rubber modified bitumens for road asphalt mixtures: A literature review," Constr. Build. Mater., vol. 49, pp. 863-881, 2013.

[15] T. Wang, F. Xiao, S. Amirkhanian, W. Huang, and M. Zheng, "A review on low temperature performances of rubberized asphalt materials," Constr. Build. Mater., vol. 145, pp. 483-505, 2017.

[16] S. Liu, W. Cao, J. Fang, and S. Shang, "Variance analysis and performance evaluation of different crumb rubber modified (CRM) asphalt," Constr. Build. Mater., vol. 23, no. 7, pp. 2701-2708, 2009, doi: https://doi.org/10.1016/j.conbuildmat.2008.12.009.

[17] S. Aflaki, P. Hajikarimi, E. H. Fini, and B. Zada, "Comparing effects of biobinder with other asphalt modifiers on low-temperature characteristics of asphalt," J. Mater. Civ. Eng., vol. 26, no. 3, 2014, doi: 10.1061/(ASCE)MT.1943-5533.0000835.

[18] B. Sengoz and G. Isikyakar, "Evaluation of the properties and microstructure of SBS and EVA polymer modified bitumen," Constr. Build. Mater., vol. 22, no. 9, pp. 1897-1905, 2008, doi: https://doi.org/10.1016/j.conbuildmat.2007.07.013.

[19] D. Fee, R. Maldonado, G. Reinke, and H. Romagosa, "Polyphosphoric acid modification of asphalt," Transp. Res. Rec., vol. 2179, no. 1, pp. 49-57, 2010.

[20] N. Baldino, D. Gabriele, C. O. Rossi, L. Seta, F. R. Lupi, and P. Caputo, "Low temperature rheology of polyphosphoric acid (PPA) added bitumen," Constr. Build. Mater., vol. 36, pp. 592-596, 2012, doi: https://doi.org/10.1016/j.conbuildmat.2012.06.011.

[21] S. Aflaki and P. Hajikarimi, "Implementing viscoelastic rheological methods to evaluate low temperature performance of modified asphalt binders," Constr. Build. Mater., vol. 36, 2012, doi: 10.1016/j.conbuildmat.2012.04.076.

[22] H. F. Brinson and L. C. Brinson, Polymer engineering science and viscoelasticity: An introduction. Springer, 2008.

[23] K. Santosh and Y.-R. Kim, "Investigation of DSR Test Methods to Determine Binder Low Temperature Properties," 2019.

[24] J. R. Koza, Genetic programming: on the programming of computers by means of natural selection, vol. 1. MIT press, 1992.

[25] A. H. Gandomi, A. H. Alavi, M. R. Mirzahosseini, and F. M. Nejad, "Nonlinear genetic- 
based models for prediction of flow number of asphalt mixtures," J. Mater. Civ. Eng., vol. 23, no. 3, pp. 248-263, 2011.

[26] A. H. Alavi and A. H. Gandomi, "A robust data mining approach for formulation of geotechnical engineering systems," Eng. Comput. Int J Comput. Eng., vol. 28, no. 3, pp. 242-274, 2011.

[27] GEPSOFT, “GeneXpro tools,” GEPSOFT, p. Bristol., 2006.

[28] I. E. Frank and R. Todeschini, The data analysis handbook. Elsevier, 1994.

[29] G. N. Smith, "Probability and statistics in civil engineering," Collins Prof. Tech. books, vol. 244, 1986.

[30] A. Golbraikh and A. Tropsha, "Beware of q2!," J. Mol. Graph. Model., vol. 20, no. 4, pp. 269-276, 2002.

[31] P. Hajikarimi, M. Rahi, and F. Moghadas Nejad, "Comparing different rutting specification parameters using high temperature characteristics of rubber-modified asphalt binders," Road Mater. Pavement Des., vol. 16, no. 4, pp. 751-766, 2015.

[32] F. M. Nejad, M. Shahabi, M. Rahi, P. Hajikarimi, and S. Kazemifard, "An investigation on the effect of SBS+vacuum bottoms residue modification on rheological characteristics of asphalt binder," Pet. Sci. Technol., vol. 35, no. 22, 2017, doi: 10.1080/10916466.2017.1384839.

[33] A. Samieadel and E. H. Fini, "Interplay between wax and polyphosphoric acid and its effect on bitumen thermomechanical properties," Constr. Build. Mater., vol. 243, p. $118194,2020$.

[34] J. F. Masson and M. Gagné, "Polyphosphoric acid (PPA)-modified bitumen: disruption of the asphaltenes network based on the reaction of nonbasic nitrogen with PPA," Energy \& fuels, vol. 22, no. 5, pp. 3402-3406, 2008.

[35] A. H. Gandomi, G. J. Yun, and A. H. Alavi, “An evolutionary approach for modeling of shear strength of RC deep beams," Mater. Struct., vol. 46, no. 12, pp. 2109-2119, 2013. 